ISSN: 2146-3042

DOI: $10.25095 /$ mufad.673739

\title{
BIST Ticaret Endeksinde Yer Alan İşletmelerin Finansal Performanslarının Entropi ve MAIRCA Yöntemleri ile Değerlendirilmesi*
}

\author{
Ejder AYÇİN * \\ Pembe GÜÇLÜ **
}

\section{$\ddot{O Z E T}$}

Bu çalışmada, Borsa İstanbul (BIST) ticaret endeksinde (XTCRT) ișlem gören ișletmelerin finansal performansları Entropi ve Çok Nitelikli İdeal-Gerçek Karşllaștırma Analizi (Multi Atributive Ideal-Real Comparative Analysis (MAIRCA)) yöntemleri bir arada kullanılarak analiz edilmiştir. Çalıșmada öncelikle finansal performansın değerlendirilmesinde kriter olarak kullanılacakolan finansal oranlar belirlenmiş vetüm işletmeler için hesaplanmıştır. Uygulamanın ilk adımında performans kriterlerine ilişkin önem ağırlıkları Entropi yöntemi ile hesaplanmıştır. Daha sonra ise işletmelere ilişkin finansal performans sıralamasının elde edilmesi için MAIRCA yönteminden yararlanılmıştır. Uygulama sonuçlarına göre, en önemli kriterler nakit oranı, asit test oranı ve aktif devir hızı olarak belirlenmiștir. Finansal performansı en yüksek olan ișletmelerinise sırasıylaMILPA Ticari ve Sinai Ürünler Pazarlama Sanayi ve Ticaret A.Ş., SANKO Pazarlama İthalat İhracat A.Ş. ve TEKNOSA İç ve Dış Ticaret A.Ş. olduğu sonucuna ulaşılmıştır.

Anahtar Kelimeler: Finansal Performans, Entropi, MAIRCA, Çok Kriterli Karar Verme

JEL Sinıflandırmasi: C44, L25
\end{abstract}

\begin{abstract}
Evaluation of Financial Performance of Businesses in BIST Trade Index with Entropy and MAIRCA Methods

\section{ABSTRACT}

In this study, the financial performances of the enterprises publicly-traded in the BIST trade index (XTCRT) were analyzed using a combination of Entropy and MAIRCA methods. In the study, firstly, financial ratios which are used as a criterion in the evaluation of financial performance were determined and calculated for all enterprises. In the first step of the application, the importance weights for performance criteria were calculated by Entropy method. Then, theMulti Atributive Ideal-Real Comparative Analysis(MAIRCA) method was used to obtain the financial performance ranking of the enterprises. According to the results of the application, the most important criteria were determined as cash ratio, acid test rate and active turnover rate. It is concluded that the enterprises with the highest financial performance are respectively, MILPA Commercial and Industrial Products Marketing Industry and Trade Inc., SANKO Marketing Import Export Inc. and TEKNOSA Domestic and Foreign Trade Inc.
\end{abstract}

Keywords: Financial Performance, Entropi, MAIRCA, Multi Criteria Decision Making

Jel Classification: C44, L25

\footnotetext{
* Makale Gönderim Tarihi: 27.03.2019, Makale Kabul Tarihi: 17.07.2019, Makale Türü: Araştırma makalesi
}

* Dr. Öğretim Üyesi, Kocaeli Üniversitesi İktisadi ve İdari Bilimler Fakültesi, ejder.aycin@kocaeli.edu.tr, ORCID ID: 0000-0002-0153-8430

** Dr. Öğr. Üyesi, Çankırı Karatekin Üniversitesi, İktisadi ve İdari Bilimler Fakültesi, pembeguclu@karatekin.edu.tr, ORCID ID: 0000-0003-0395-7433 


\section{GíRiş}

İşletme performansının en önemli göstergelerinden biri olan finansal performans, bir işletmenin fon kaynaklarını ne derece etkin kullandığını ortaya koyan önemli bir kavramdır. Finansal performansın belirlenmesi ya da ölçülmesi, içerisinde çok sayıda kriteri bulunduran bir karar verme problemi olarak tanımlanabilir. Dolayısıyla finansal performans değerlendirilirken çok kriterli karar verme (ÇKKV) yöntemlerinden sıklıkla yararlanılmaktadır.

$\mathrm{Bu}$ çalışmada BIST ticaret endeksinde yer alan işletmelerin finansal performanslarının değerlendirilmesinde ÇKKV yöntemlerinden bütünleşik olarak yararlanılmıştır. Öncelikle, finansal performans kriterlerinin belirlenmesi ve mevcut çalışmanın literatürdeki yerinin gösterilmesi amacıyla kapsamlı bir literatür taraması gerçekleştirilmiştir. Belirlenen performans kriterlerine ilişkin kriter ağırlıkları, objektif bir kriter ağırlıklandırma yöntemi olan Entropi yöntemiyle hesaplanmıştır. Herhangi bir subjektif değerlendirmeye ihtiyaç duyulmaması ve hesaplamaların yapılabilmesi için karar matrisinin yeterli olması nedeniyle, kriter ağırlıklarının hesaplanmasında Entropi yöntemi tercih edilmiştir. Uygulama kapsamında yer alan işletmelerin finansal performans değerleri ve sıralamalarıÇok Nitelikli İdeal-Gerçek Karşılaştırma Analizi (Multi Atributive Ideal-Real Comparative Analysis (MAIRCA)) yöntemiyle elde edilmiştir. Karar alternatiflerini kriterlere göre değerlendirirken, ideal derecelendirmelere yakınlıkları dikkate alarak hesaplama yapan bir yöntem olması nedeniyle MAIRCA yöntemi tercih edilmiştir. Ayrıca mevcut çalışmanın yapıldığı tarih itibariyle, ÇKKV ile ilgili ulusal literatürde MAIRCA yöntemiyle gerçekleştirilen herhangi bir çalışma olmaması bakımından, mevcut çalışmanın literatüre katkı sağlaması beklenmektedir.

\section{LITERATÜR TARAMASI}

Finansal performansın ölçülmesini ana ve alt amaç olarak benimsemiş olan, ulusal ve uluslararası literatürde birçok çalışma bulunmaktadır. Web of Science ve Google Akademik’te finansal performans sorgulamasıyla tespit edilen çalışmalar aşağıdaki gibi özetlenmeye çalışılmıştır.

\begin{tabular}{|l|l|c|}
\hline Yazar(lar) & Finansal Performans Kriterleri & $\begin{array}{c}\text { Kullanılan } \\
\text { Yöntemler }\end{array}$ \\
\hline \hline $\begin{array}{l}\text { Feng ve Wang } \\
\text { (2000) }\end{array}$ & $\begin{array}{l}\text { Kisa-Uzun Dönem Likidite durumu, karllılı, borç devir hızı, } \\
\text { yatırımın geri dönüşü, Assets and stockholder's Turnover ile } \\
\text { ilgili çeşitli oranlar }\end{array}$ & TOPSIS \\
\hline Kalogeras vd. (2005) & $\begin{array}{l}\text { Karlılık, Likidite, yönetsel performans kategorilerinde toplam } \\
11 \text { rasyo }\end{array}$ & PROMETHEE II \\
\hline \hline Ho ve Wu(2006) & $\begin{array}{l}\text { Karlılık, kaldıraç, likidite, ekonomik yapı ve } \\
\text { büyüme oranlarından toplam 59 oran }\end{array}$ & Gri İlişkisel Analiz \\
\hline \hline Wang (2008) & $\begin{array}{l}\text { Finansal yapı, ödeme gücü, ciro ve karlılık ana kriterleri ve } \\
\text { finansal oranlardan oluşan alt kriterler }\end{array}$ & $\begin{array}{c}\text { Gri İlişkisel Analiz } \\
\text { ve Bulanık } \\
\text { TOPSIS }\end{array}$ \\
\hline
\end{tabular}




\begin{tabular}{|c|c|c|}
\hline $\begin{array}{l}\text { Ertuğrul ve } \\
\text { Karakaşoğlu (2009) }\end{array}$ & \begin{tabular}{|l} 
Likidite, faaliyet oranları, ekonomik yapı, karlılık ve büyüme \\
ile ilgili toplam 18 rasyo
\end{tabular} & $\begin{array}{l}\text { Bulanık AHP ve } \\
\text { TOPSIS }\end{array}$ \\
\hline Tseng vd. (2009) & \begin{tabular}{|l} 
Özsermaye karlılığı (ROE) , Sermaye Yapısı, Piyasa Değeri, \\
Nakit devir hızı
\end{tabular} & $\begin{array}{c}\text { AHP, DEA } \\
\text { TOPSIS }\end{array}$ \\
\hline Tung ve Lee (2009) & $\begin{array}{l}\text { Finansal Yapı, Yönetim etkinliği (Devir Hızı), Likidite ve } \\
\text { Karlılık rasyolarından toplam } 17 \text { rasyo }\end{array}$ & $\begin{array}{c}\text { Gri Temel } \\
\text { Bileşenler Analizi, } \\
\text { grey absolute degree } \\
\text { of incidence }\end{array}$ \\
\hline Wang (2009) & $\begin{array}{l}\text { Finansal yapı, ödeme gücü, ciro ve karlılık ana kriterleri ve } \\
\text { finansal oranlardan oluşan alt kriterler }\end{array}$ & $\begin{array}{c}\text { Bulanık Gri } \\
\text { İlişkisel Analiz }\end{array}$ \\
\hline $\begin{array}{l}\text { Yalçın Seçme vd. } \\
\text { (2009) }\end{array}$ & \begin{tabular}{|l} 
Sermaye yeterliliği, varlık kalitesi,likidite,karlılık, gelir yapısı \\
ve hisse durumu ile ilgili 27 oran
\end{tabular} & $\begin{array}{l}\text { Bulanık AHP, } \\
\text { TOPSIS }\end{array}$ \\
\hline Tung ve Lee (2010) & Farklı kategorilerde 27 finansal oran & $\begin{array}{l}\text { Gri Faktör Analizi, } \\
\text { Mutlak gri insidans } \\
\text { derecesi }\end{array}$ \\
\hline Wang veLee (2010) & \begin{tabular}{|l} 
Finansal yapı oranları, ödeme gücü oranları, ciro oranları ve \\
karlılık oranları
\end{tabular} & $\begin{array}{l}\text { Bulanık Gri } \\
\text { İlişkisel Analiz }\end{array}$ \\
\hline Akyüz vd.(2011) & $\begin{array}{l}\text { Likidite, finansal yap1, faaliyet ve karlılık ile ilgili toplam } 19 \\
\text { oran }\end{array}$ & TOPSIS \\
\hline $\begin{array}{l}\text { Bülbül ve Köse } \\
\text { (2011) }\end{array}$ & $\begin{array}{l}\text { Cari oran, likidite oranı, nakit oran, toplam borç/ toplam aktif } \\
\text { oranı, aktif karlılığı, satış karlılığı, özsermeye karlılığı ve net } \\
\text { satışlar/toplam aktif oranı }\end{array}$ & $\begin{array}{l}\text { ELECTRE ve } \\
\text { TOPSIS }\end{array}$ \\
\hline Peker veBaki (2011) & Likidite, karlılık ve kaldıraç oranlarından toplam 10 tanesi & Gri İlişkisel Analiz \\
\hline Kung vd. (2011) & $\begin{array}{l}\text { Cari oran, borç oranı, özsermaye/borç oranı, satış karlılık oranı, } \\
\text { aktif karlılık oranı ve vergi öncesi kar }\end{array}$ & $\begin{array}{l}\text { Bulanık AHP ve } \\
\text { Bulanık TOPSIS }\end{array}$ \\
\hline $\begin{array}{l}\text { Balezentis vd. } \\
(2012)\end{array}$ & $\begin{array}{l}\text { Satış karı, aktif karlılık oranı, kaldıraç oranı, carioran, alacak } \\
\text { devir hızı oranı ve özsermaye karlılık oranı }\end{array}$ & $\begin{array}{l}\text { Bulanık VIKOR, } \\
\text { Bulanık TOPSIS } \\
\text { ve Bulanık ARAS }\end{array}$ \\
\hline $\begin{array}{l}\text { Bölükbaş vd. } \\
\text { (2012) }\end{array}$ & \begin{tabular}{|l} 
Cari Rasyo, Nakit Oranı Asit Test Rasyo, Net Satışlar/Ortalama \\
Alacaklar, Stok Devir Hızı, Varlık Devir Hızı, Finansal Kaldıraç, \\
Hisse Başına Kar, Özsermaye Karlılığı, Net Satışlar/Özsermaye
\end{tabular} & $\begin{array}{c}\text { Bulanık AHP } \\
\text { PROMETHEE } \\
\text { ELECTRE ve } \\
\text { VIKOR }\end{array}$ \\
\hline Bulgurcu (2012) & $\begin{array}{l}\text { Cari Rasyo , Asit Test Rasyo, Toplam Borç Oranı (Kaldıraç } \\
\text { Oranı), Borç Özsermaye Oranı, Dönen Varlık Devir Hızı, Duran } \\
\text { Varlık Devir Hızı, Net Kar Marjı, Özsermaye Karlılığı, İşletme } \\
\text { Sermayesi Devir Hızı, Aktif Getiri Oranı (ROA) }\end{array}$ & TOPSIS \\
\hline Elitaş vd.(2012) & Likidite, karlılık ve kaldıraç oranlarından toplam 10 tanesi & Gri İlişkisel Analiz \\
\hline Ignatius vd. (2012) & $\begin{array}{l}\text { Satış büyüklüğü, aktif karlılık oranı, öz sermaye karlılık oranı, } \\
\text { cari oran ve varlık devir hızı }\end{array}$ & PROMETHEE II \\
\hline
\end{tabular}




\begin{tabular}{|c|c|c|}
\hline Lee vd. (2012) & $\begin{array}{l}\text { Likidite, karlılık, yatırımın geri dönüşü, etkinlik, finansal } \\
\text { kaldıraç ve nakit akışı ana kriterleri altında toplam } 25 \text { oran }\end{array}$ & $\begin{array}{l}\text { Entropi ve Gri } \\
\text { İlişkisel Analiz }\end{array}$ \\
\hline Özden vd. (2012) & $\begin{array}{l}\text { Cari oran, alacak devir süresi, stok devir süresi, ticari borç } \\
\text { devir süresi, borçlanma oran1, özsermaye karlılı̆ı, esas faaliyet } \\
\text { kar marjı ve faaliyet maliyet oranı }\end{array}$ & VIKOR \\
\hline Yalçın vd. (2012) & $\begin{array}{l}\text { Varlık karlılı̆̆ı, özsermaye karlılı̆̆ı, hisse başına karlılık, F/K } \\
\text { oranı, ekonomik katma değer, piyasa katma değeri, nakit katma } \\
\text { değeriveyatırımın nakit karlılığ } 1\end{array}$ & $\begin{array}{l}\text { Bulanık AHP, } \\
\text { VIKOR ve TOPSIS }\end{array}$ \\
\hline Doğan (2013) & $\begin{array}{l}\begin{array}{l}\text { Likidite, kaldıraç, varlık kalitesi ve karlılık oranlarından } 10 \\
\text { tanesi }\end{array} \\
\end{array}$ & Gri İlişkisel Analiz \\
\hline Akhisar (2014) & $\begin{array}{|lcrr|}\text { AlınanPrimler/Özkaynaklar, } & \text { Özkaynaklar/ } & \text { Teknik } & \text { Karşllıklar, } \\
\text { Özkaynaklar/Toplam } & \text { Varlıklar, } & \text { Finansal } \\
\text { Kar(Zarar)/Özkaynaklar, } & \text { Zarar } & \text { Oranı, } & \text { Teknik } \\
\text { Kar(Zarar)/Finansal } & \text { Kar(Zarar), } & \text { Teknik } \\
\text { Kar(Zarar)/Özkaynaklar, Nakit } & \text { ve Nakit } & \text { Benzerleri/Toplam } \\
\text { Varlıklar, Kar Dağıtmama Oranı } & & \end{array}$ & ANP \\
\hline Çelen (2014) & \begin{tabular}{|l} 
Sermaye oranları, bilanço oranları, varlık kalitesi, likidite, \\
karlılık ve gelir-harcama yapısı oranlarından toplam 29 oran
\end{tabular} & $\begin{array}{l}\text { Bulanık AHP, } \\
\text { TOPSIS }\end{array}$ \\
\hline $\begin{array}{l}\text { Ecer ve } \\
\text { Günay (2014) }\end{array}$ & $\begin{array}{l}\text { Likidite, finansal yapı, faaliyet ve karlılık } \\
\text { Oranlarından } 17 \text { tanesi }\end{array}$ & Gri İlişkisel Analiz \\
\hline Ergül (2014) & $\begin{array}{l}\text { Cari oran, likidite oranı, borç oranı, duran varlık/ uzun vadeli } \\
\text { borçlar oranı, SMM/ ortalama stokoranı, net satışlar/toplam aktif } \\
\text { oran1, faaliyet giderleri/net satı̧lar oranı, satışların maliyeti/net } \\
\text { satışlar, personel giderleri/net satışlar oranı, net kar/net satışlar } \\
\text { oranı, net kar/toplam aktif oranı }\end{array}$ & $\begin{array}{l}\text { ELECTRE ve } \\
\text { TOPSIS }\end{array}$ \\
\hline Esbouei vd. (2014) & $\begin{array}{l}\text { Aktif karlılı̆̆ı, özsermaye karlılı̆̆ı, F/K oranı, ekonomik katma } \\
\text { değer, piyasa katma değeri, nakit katma değer, gerçek katma } \\
\text { değer, Tobin'sQ endeksi ve hissedar değeri }\end{array}$ & $\begin{array}{l}\text { Bulanık ANP ve } \\
\text { Bulanık VIKOR }\end{array}$ \\
\hline $\begin{array}{l}\text { Ghadikolaei vd. } \\
\text { (2014) }\end{array}$ & $\begin{array}{l}\text { Aktif karlılığı, özsermaye karlılığı, F/K oranı, ekonomik katma } \\
\text { değer, piyasa katma değeri, nakit katma değer, gerçek katma } \\
\text { değer, Tobin's Q endeksi ve hissedar değeri }\end{array}$ & $\begin{array}{l}\text { Bulanık AHP, } \\
\text { Bulanık VIKOR, } \\
\text { Bulanık ARAS, } \\
\text { Bulanık COPRAS }\end{array}$ \\
\hline Mandic vd. (2014) & $\begin{array}{l}\text { Özsermaye, portföy, kaynaklar, likit varlıklar, nakit akışı, net } \\
\text { faiz geliri, vergi öncesi kar ve ana faaliyet geliri }\end{array}$ & $\begin{array}{l}\text { Bulanik AHP ve } \\
\text { TOPSIS }\end{array}$ \\
\hline $\begin{array}{l}\text { Moghimi ve } \\
\text { Anvari (2014) }\end{array}$ & $\begin{array}{l}\text { Likidite, finansal kaldıraç, faaliyet ve karlılık ile ilgili toplam } \\
16 \text { oran }\end{array}$ & $\begin{array}{l}\text { Bulanık AHP, } \\
\text { TOPSIS }\end{array}$ \\
\hline $\begin{array}{l}\text { Ömürbek ve } \\
\text { Mercan (2014) }\end{array}$ & $\begin{array}{l}\text { Cari oran, nakit oranı, yabancı kaynaklar/toplam aktif oranı, stok } \\
\text { devir hızı, özkaynak devir hızı, net kar/özkaynak, faaliyet } \\
\text { karı/net satışlar, net kar/net satışlar ve smm/net satışlar oranı }\end{array}$ & $\begin{array}{l}\text { TOPSIS ve } \\
\text { ELECTRE }\end{array}$ \\
\hline $\begin{array}{l}\text { Saldanli ve Sirma } \\
\text { (2014) }\end{array}$ & $\begin{array}{l}\text { Cari oran, nakit oran, kaldıraç oranı, finansman } \\
\text { giderleri/toplam borç oranı, aktif devri hızı, özsermaye devir } \\
\text { hızı, aktif karlılı̆̆ ve özsermaye karlılığı }\end{array}$ & TOPSIS \\
\hline
\end{tabular}




\begin{tabular}{|c|c|c|}
\hline $\begin{array}{l}\text { Shen ve Tzeng } \\
(2014)\end{array}$ & $\begin{array}{l}\text { Sermaye yeterliliği, varlık kalitesi, kazanç ve karlılık, likidite, } \\
\text { faiz oranı duyarlılığı, büyüme ana kriterleri ve bu kriterlerin } \\
\text { altında yer alan alt kriterler }\end{array}$ & $\begin{array}{c}\text { RSA, DRSA, } \\
\text { DEMATEL } \\
\text { Tabanlı ANP ve } \\
\text { VIKOR }\end{array}$ \\
\hline Tayyar vd. (2014) & Likidite, mali yapı, faaliyet ve karlılık oranlarından 12 tanesi & $\begin{array}{l}\text { AHP ve Gri } \\
\text { İlişkisel Analiz }\end{array}$ \\
\hline Wang (2014) & $\begin{array}{l}\text { Finansal yap1, ciro, karlılık ve borç ödeme yeteneği ana } \\
\text { kriterleri ve alt kriterler }\end{array}$ & $\begin{array}{l}\text { Bulanık TOPSIS } \\
\text { ve Gri İlişkisel } \\
\text { Analiz }\end{array}$ \\
\hline Fenyves vd. (2015) & $\begin{array}{l}\text { Cari oran, asit test oranı, net işletme sermayesi, borçlar / toplam } \\
\text { pasif, faaliyet kaldıraç derecesi, Finansal kaldıraç derecesi, } \\
\text { özkaynak değişimi, faaliyetl karı(zararı) değişikliği, net } \\
\text { satıştaki değişim, stok devir hızı, alacak devir hızı }\end{array}$ & $\begin{array}{l}\text { Veri Zarflama } \\
\text { Analizi }\end{array}$ \\
\hline Hsu vd. (2015) & $\begin{array}{l}\text { Faaliyet kabiliyeti, ödeme gücü yeteneği ve karlılık ana } \\
\text { kriterleri altında } 22 \text { oran }\end{array}$ & $\begin{array}{l}\text { Gri İlişkisel Analiz } \\
\text { ve TOPSIS }\end{array}$ \\
\hline İç vd. (2015) & $\begin{array}{l}\text { Likidite, finansal yapı, faaliyet ve karlılık ile ilgili toplam } 12 \\
\text { rasyo }\end{array}$ & $\begin{array}{l}\text { TOPSIS, Gri } \\
\text { İlişkisel Analiz, } \\
\text { MOORA ve } \\
\text { VIKOR }\end{array}$ \\
\hline İslamoğlu vd. (2015) & $\begin{array}{l}\text { Likidite, kaldıraç, varlık ve sermaye yapısı, ciro ve karlılık ana } \\
\text { kriterleri altında } 16 \text { oran }\end{array}$ & Entropi ve TOPSIS \\
\hline Kazan vd. (2015) & $\begin{array}{l}\text { Büyüme oranları, değer oranları, finansal yapı oranları, faaliyet } \\
\text { oranları, karlılık oranları ve likidite oranlarından toplam } 49 \\
\text { oran }\end{array}$ & $\begin{array}{l}\text { AHP, } \\
\text { PROMETHEE }\end{array}$ \\
\hline $\begin{array}{l}\text { Shen ve Tzeng } \\
\text { (2015a) }\end{array}$ & $\begin{array}{l}\text { Sermaye yapısı, geri ödeme yeteneği, operasyonel etkinlik, } \\
\text { karlılık ve nakit akışı ile ilgili toplam } 19 \text { oran }\end{array}$ & $\begin{array}{l}\text { DRSA, FCA, } \\
\text { DANP }\end{array}$ \\
\hline $\begin{array}{l}\text { Shen ve Tzeng } \\
(2015 b)\end{array}$ & $\begin{array}{l}\text { Sermaye yeterliliği, varlık kalitesi, kazanç ve karlılık, likidite, } \\
\text { faiz oranı duyarlılığı ve büyüme ile ilgili toplam } 25 \text { oran }\end{array}$ & $\begin{array}{l}\text { DRSA, DANP, } \\
\text { VIKOR }\end{array}$ \\
\hline Tavana vd. (2015) & \begin{tabular}{|l} 
Hisse başına kar, fiyat-kazanç oranı, satışlardaki büyüme, borç \\
rasyosu (kaldıraç oranı), likidite derecesi, faaliyet bütçesi
\end{tabular} & $\begin{array}{l}\text { DEMATEL· } \\
\text { Bulanık ANP } \\
\text { Bulanık DEA }\end{array}$ \\
\hline $\begin{array}{l}\text { Yükçü ve } \\
\text { Kaplanoğlu (2015) }\end{array}$ & $\begin{array}{l}\text { Borç ödeme gücü, karlılık, faaliyet kapasitesi, iş geliştirme } \\
\text { kapasitesi, yapısal sağlamlık ve } \\
\text { sermaye artırma kapasitesi ana kriterleri altında toplam } 30 \text { oran }\end{array}$ & $\begin{array}{c}\text { MOORA, } \\
\text { TOPSIS, VIKOR, } \\
\text { Gri } \\
\text { İlişkisel Analiz }\end{array}$ \\
\hline $\begin{array}{l}\text { Visalakshmi vd. } \\
\text { (2015) }\end{array}$ & $\begin{array}{l}\text { Karlılık, likidite, borç teminat, etkinlik ve yatırım değerleme ile } \\
\text { ilgili toplam } 16 \text { oran }\end{array}$ & $\begin{array}{l}\text { Bulanik } \\
\text { DEMATEL, } \\
\text { TOPSIS }\end{array}$ \\
\hline $\begin{array}{l}\text { Wiratno vd. } \\
(2015)\end{array}$ & Fon tutarı, karlılık oranı, özkaynak paylaşımı, kar & ANP \\
\hline Zhao ve Li (2015) & $\begin{array}{l}\text { Total asset turnover ratio, Profit ratio of sales, Return on assets, } \\
\text { Operating cash index, Total industrial output value }\end{array}$ & $\begin{array}{l}\text { Dengeli Puan } \\
\text { Kartı, Delfi, AHP, } \\
\text { Bulanık TOPSIS }\end{array}$ \\
\hline
\end{tabular}




\begin{tabular}{|c|c|c|}
\hline $\begin{array}{l}\text { Chang ve Tsai } \\
\text { (2015) }\end{array}$ & $\begin{array}{l}\text { Hizmet, performans, profesyonellik, risk kontörlü ve güven } \\
\text { ana kriterlerinin altında toplam } 25 \text { alt kriter }\end{array}$ & AHP ve VIKOR \\
\hline Erdoğan vd. (2016) & $\begin{array}{l}\text { Nakit oranı, asit test oranı, cari oran, finansal kaldıraç oranı, } \\
\text { aktif devir hızı, net kar/toplam aktif, net kar/ özsermaye, net } \\
\text { kar/net satışlar }\end{array}$ & $\begin{array}{l}\text { TOPSIS, VIKOR } \\
\text { ve ELECTRE }\end{array}$ \\
\hline Farokh vd. (2016) & $\begin{array}{l}\text { Likidite, finansal kaldıraç, karlılık ve büyüme ile ilgili } \\
\text { toplam } 12 \text { oran }\end{array}$ & $\begin{array}{c}\text { Bulanık AHP, } \\
\text { TOPSIS, VIKOR }\end{array}$ \\
\hline Javadin vd. (2016) & EVA, MVA, REVA, TVA, CVA, EEVA, CSV ve Tobin's Q & $\begin{array}{c}\text { Bulanık AHP } \\
\text { Bulanık COPRAS }\end{array}$ \\
\hline Meydan vd. (2016) & $\begin{array}{l}\text { Likidite, finansal yap1, faaliyet ve karlılık oranlarından } \\
\text { toplam } 20 \text { adet oran }\end{array}$ & Gri İlişkisel Analiz \\
\hline Ömürbek vd. (2016) & $\begin{array}{l}\text { Sermaye, hisse senedi, piyasa değeri, satış geliri, personel } \\
\text { sayısı, net kar marjı, cari oran, özsermaye karlılığı, satışların } \\
\text { karlılığı ve net satışlar/personel sayısı oranı }\end{array}$ & $\begin{array}{l}\text { Entropi, MAUT ve } \\
\text { SAW }\end{array}$ \\
\hline $\begin{array}{l}\text { Ömürbek ve Eren } \\
\text { (2016) }\end{array}$ & $\begin{array}{l}\text { Cari oran, nakit oran, asit test oranı, stoklar/toplam aktif, öz } \\
\text { kaynak/toplam aktif, borçlanma oranı, finansal kaldıraç oranı, } \\
\text { ôz kaynak karlılığı, net kar marjı, fiyat kazanç oranı, net } \\
\text { çalışma sermayesi devir hızı, stok devir hızı ve alacak devir } \\
\text { hızı }\end{array}$ & $\begin{array}{l}\text { PROMETHEE, } \\
\text { MOORA ve } \\
\text { COPRAS }\end{array}$ \\
\hline Shaverdi vd. (2016) & 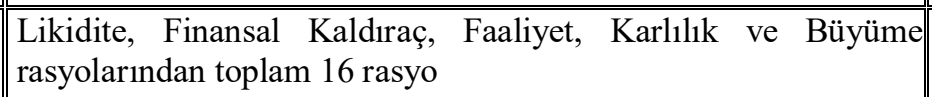 & $\begin{array}{l}\text { Bulanık AHP, } \\
\text { Bulanık TOPSIS }\end{array}$ \\
\hline Varmazyar vd. (2016) & $\begin{array}{l}\text { Net kâr oran1, Sözleşme değeri, Maliyet performansı endeksi, } \\
\text { Beklenmeyen maliyet (UC) Endeksi }\end{array}$ & $\begin{array}{l}\text { DEMATEL, ANP, } \\
\text { ARAS, COPRAS, } \\
\text { MOORA, TOPSIS }\end{array}$ \\
\hline Wanke vd. (2016) & $\begin{array}{l}\text { Sermaye yeterliliği, varlık kalitesi, yönetim, karlılık, likidite ve } \\
\text { piyasa riskine karşı duyarlılık ana kriterleri altında toplam } 25 \\
\text { oran }\end{array}$ & $\begin{array}{l}\text { Bulanık AHP ve } \\
\text { TOPSIS }\end{array}$ \\
\hline $\begin{array}{l}\text { Akçakanat vd. } \\
\text { (2017) }\end{array}$ & $\begin{array}{l}\text { Toplam aktifler, toplam krediler ve alacaklar, toplam mevduat, } \\
\text { özkaynak toplamı, şube vepersonel sayısı }\end{array}$ & $\begin{array}{l}\text { Entropi ve } \\
\text { WASPAS }\end{array}$ \\
\hline $\begin{array}{l}\text { Aytekin ve } \\
\text { Karamaşa (2017) }\end{array}$ & $\begin{array}{l}\text { Cari oran, çok sınırlı likidite oranı, borç oranı,satışların karlılığı, } \\
\text { özsermaye karlıllığı ve yatırımın geri dönüşü }\end{array}$ & $\begin{array}{l}\text { Shannon Entropisi } \\
\text { ve TOPSIS }\end{array}$ \\
\hline Dinçer vd. (2017) & ROA, ROE, Borç Oranı (Kaldıraç Oranı), Cari Rasyo, Kar artışı & $\begin{array}{l}\text { Bulanık } \\
\text { DEMATEL, } \\
\text { Bulanık ANP, } \\
\text { MOORA }\end{array}$ \\
\hline Hadelan vd. (2017 & Cari rasyo, kaldıraç oranı, Varlık devir hızı, ROA & AHP \\
\hline $\begin{array}{l}\text { Orçun ve Eren } \\
(2017)\end{array}$ & $\begin{array}{l}\text { Likidite oranları, aktif devir hızı, kaldıraç, özsermaye devir } \\
\text { hızı, satışları karlıl1ı̆̆,özsermaye karlılığı, esas faaliyet } \\
\text { karlılık oranları olmak üzere toplam } 18 \text { oran }\end{array}$ & TOPSIS \\
\hline $\begin{array}{l}\text { Önder ve } \\
\text { Altıntaş (2017) }\end{array}$ & $\begin{array}{l}\text { Varlık büyüme oran1, maliyet/net satış oran1, aktif karlılı̆̆ı, net } \\
\text { kar marj1, özsermaye karlılığı,cari oran, asit-test oran ve duran } \\
\text { varlık/toplam varlık oranı }\end{array}$ & $\begin{array}{l}\text { ANP ve Gri } \\
\text { İlişkisel Analiz }\end{array}$ \\
\hline
\end{tabular}




\begin{tabular}{|c|c|c|}
\hline $\begin{array}{l}\text { Robelo vd. } \\
(2017)\end{array}$ & $\begin{array}{l}\text { Risk durumu, karlılık, borç yapısı, likidite ve faaliyetler ile } \\
\text { ilgili toplam } 16 \text { kriter }\end{array}$ & PROMETHEE II \\
\hline Toma (2017) & $\begin{array}{l}\text { Emek yoğunluğu, sermaye yoğunluğu, Girdi/çıtıtı oranı, Cost- } \\
\text { Revenue with subsidies Ratio, Cost-Revenue without } \\
\text { subsidies Ratio, Finansal Stres Rasyosu, borçsuzluk rasyosu } \\
\text { (likidite), Kaldıraç oranı }\end{array}$ & $\begin{array}{l}\text { Temel Bileşenler } \\
\text { Analizi, } \\
\text { TOPSIS, k- } \\
\text { ortalama } \\
\text { Kümeleme }\end{array}$ \\
\hline Ünlü vd. (2017) & $\begin{array}{l}\text { Özsermaye karlılığı, aktif karlılığ1, satışların karlılığ1, faaliyet } \\
\text { nakit akımı/varlık toplamı,piyasa katma değeri, yatırımın nakit } \\
\text { karlılığ1 ve nakit katma değer }\end{array}$ & Critic ve TOPSIS \\
\hline Ayçin (2018) & \begin{tabular}{|l} 
Fiyat kazanç oranı, piyasa değeri/defter değeri, beta endeksi, \\
temettü verimliliği, özsermaye karlılık oranı (ROE), piyasa \\
katma değeri (MVA)
\end{tabular} & $\begin{array}{l}\text { ENTROPI } \\
\text { GRİ İLİŞKİSEL } \\
\text { ANALIZ }\end{array}$ \\
\hline $\begin{array}{l}\text { Dong vd. } \\
(2018)\end{array}$ & $\begin{array}{l}\text { Hisse senedi getiri oranı, toplam varlıklar getirisi, aktif devir } \\
\text { hızı, alacak devir hızı, borç/toplam aktif oranı, faiz karşılama } \\
\text { oranı, ana faaliyet gelir oranındaki artış,paydaş değeri } \\
\text { güçlendirme ve iyileştirme oranı }\end{array}$ & $\begin{array}{l}\text { Kosinüs benzerliği } \\
\text { tabanlı } \\
\text { QUALIFLEX }\end{array}$ \\
\hline Ege ve Yaman (2018) & $\begin{array}{l}\text { Aktif karlılığı, alacak devir hızı oranı, toplam borç oranı, } \\
\text { bor./özsermaye oranı, cari oran, F/K oranı, pay başına kazanç } \\
\text { oranı, özsermayekarlılığı, PD/DD oranı ve stok devir hızı } \\
\text { oranı }\end{array}$ & $\begin{array}{l}\text { TOPSIS ve } \\
\text { MOORA }\end{array}$ \\
\hline $\begin{array}{l}\text { Erdoğan ve } \\
\text { Yamaltdinova } \\
(2018)\end{array}$ & $\begin{array}{l}\text { Likidite, finansal yapı, devir hızı ve karlılık oranlarından } \\
\text { toplam } 12 \text { adet oran }\end{array}$ & TOPSIS \\
\hline $\begin{array}{l}\text { Gök Kısa ve Perçin } \\
\text { (2018) }\end{array}$ & $\begin{array}{l}\text { Net satışlar, varlıklar, piyasa değeri, çalışan sayısı, kaldıraç } \\
\text { oranı, aktif karlılığı ve net karmarjı }\end{array}$ & Entropi ve VIKOR \\
\hline Günay vd.(2018) & $\begin{array}{l}\text { Likidite, finansal yap1, devir hızı ve karlılık oranlarından toplam } \\
14 \text { adet oran }\end{array}$ & Gri İlişskisel Analiz \\
\hline Kaplanoğlu (2018) & 18 adet nakit akış oranı & $\begin{array}{l}\text { ARAS ve } \\
\text { COPRAS }\end{array}$ \\
\hline $\begin{array}{l}\text { Karaoğlan ve Şahin } \\
(2018)\end{array}$ & $\begin{array}{l}\text { Likidite, finansal yapı, devir hızı ve karlılık oranlarından toplam } \\
15 \text { oran }\end{array}$ & $\begin{array}{l}\text { TOPSIS, Gri } \\
\text { İlişkisel Analiz, } \\
\text { VIKOR, MOORA }\end{array}$ \\
\hline $\begin{array}{l}\text { K1z1ltoprak ve } \\
\text { Aksoy (2018) }\end{array}$ & \begin{tabular}{|l} 
Toplam aktif karlılığı, öz kaynak kârlılığı, toplamsatış kârlılığı \\
ve piyasa değerinin defter değerine oranı
\end{tabular} & Regresyon Analizi \\
\hline Konak vd.(2018) & $\begin{array}{l}\text { Likidite, finansal yapı, devir hızı ve karlılık oranlarından toplam } \\
10 \text { adet oran }\end{array}$ & TOPSIS MOORA \\
\hline $\begin{array}{l}\text { Korkmaz ve gürer } \\
(2018)\end{array}$ & $\begin{array}{l}\text { Kaldıraç oranı, özsermaye/ toplam aktf,, kısa vadeli } \\
\text { borçlar/toplam borç, net geli/toplam aktif, net çalışma sermayesi/ } \\
\text { net toplam varlık }\end{array}$ & TOPSIS \\
\hline $\begin{array}{l}\text { Tütüncü ve Uysal } \\
\text { (2018) }\end{array}$ & $\begin{array}{l}\text { Cari oran, asit-test oran, alacak devir hızı oranı, varlık devir } \\
\text { hızı oranı, kaldıraç oranı, aktifkarlılığı, özsermaye karlılığı ve } \\
\text { satışların karlığı }\end{array}$ & TOPSIS \\
\hline
\end{tabular}




\begin{tabular}{|c|c|c|}
\hline $\begin{array}{l}\text { Uludağ ve Ece } \\
\text { (2018) }\end{array}$ & $\begin{array}{l}\text { Sermaye yeterliliği, aktif kalitesi, büyüklük, likidite, karlılık, } \\
\text { büyüme oranı ve risk ana kriterleri altında toplam } 49 \text { adet oran }\end{array}$ & TOPSIS \\
\hline Üçüncü vd. (2018) & $\begin{array}{l}\begin{array}{l}\text { Likidite, Finansal Yapı , Faaliyet ve Karlılık rasyolarından } \\
\text { toplam } 10 \text { rasyo }\end{array} \\
\end{array}$ & TOPSIS \\
\hline $\begin{array}{l}\text { Yalçın ve Ünlü } \\
\text { (2018) }\end{array}$ & $\begin{array}{l}\text { ROA, ROE, ROS, nakit akışı/ toplam varlık, EVA, REVA, } \\
\text { MVA, CFROI, CVA }\end{array}$ & $\begin{array}{l}\text { VIKOR ve } \\
\text { CRITIC }\end{array}$ \\
\hline Y1ldırım vd. (2018) & $\begin{array}{l}\text { Cari oran, asit-test oranı, alacak devir hızı, finansal kaldıraç } \\
\text { oranı, satışların karlılığı, aktif karlılığı, özsermaye karlılığı, F/K } \\
\text { oranı ve PD/DD oranı }\end{array}$ & Entropi ve TOPSIS \\
\hline Atukalp (2019) & $\begin{array}{l}\text { Cari Oran, Maddi Duran Varlıkların Özkaynaklara Oranı, } \\
\text { Finansal Kaldıraç Oranı, Alacak Devir Hızı, Aktif Devir Hızı, } \\
\text { Aktif Kârlılığı, Özsermaye Kârlılığı }\end{array}$ & Multi-MOORA \\
\hline $\begin{array}{l}\text { Özçelik ve } \\
\text { Küçükçakal (2019) }\end{array}$ & $\begin{array}{l}\text { Hisse Başına Kar, Aktif Devir Hızı, Kaldıraç Oranı, Aktif } \\
\text { Karlılık Oranı, Özsermaye Karlılığı, Cari Oran }\end{array}$ & TOPSIS \\
\hline
\end{tabular}

\section{ENTROPI}

1865 y1lında literatüre giren Entropi kavramı, evrende kendi haline ve doğal şartlara bırakılan tüm sistemlerin zaman içerisinde dağınıklığa ve düzensizliğe uğrayıp bozulması olarak tanımlanmıştır. Sonraki yıllarda Shannon bu kavramı, kesikli olasılık dağılımı ile açıklanmış ve belirsizliğin bir ölçüsü olarak tanımlanmıştır (Zhang vd., 2011: 444).

Birçok kriteri içerisinde bulunduran karar verme problemlerinde, kriter ağırlıklarının hesaplanması konusunda, Entropi yöntemi literatürde yer alan ağırlık hesaplama yöntemlerinden objektif olanlar kategorisinde değerlendirilmektedir. Entropi yönteminde karar probleminde yer alan kriterlere ilişkin ağırlıklarının hesaplanması için, karar matrisindeki veriler kullanılmaktadır. Başka herhangi bir subjektif değerlendirmeye ihtiyaç duyulmaması nedeniyle yöntemin uygulanabilirliği oldukça kolaydır. Entropi yöntemi beş aşamadan oluşan bir uygulama sürecine sahiptir (Erol ve Ferrell, 2009: 1196-1197; Wang ve Lee, 2009: 8982; Özdağoğlu vd..2017: 346-347)

1. Aşama: Karar Matrisinin Oluşturulması: Yöntemin ilk aşamasında $x_{i j}$ değerlerinden oluşan ve $D$ ile simgelenen karar matrisi Eşitlik (1)'de gösterilen şekilde oluşturulur.

$$
\mathrm{D}=\underset{\mathrm{A}_{2}}{\mathrm{~A}_{1}} \underset{\mathrm{A}_{\mathrm{m}}}{\mathrm{A}_{1}}\left[\begin{array}{cccc}
\mathrm{x}_{11} & \mathrm{x}_{12} & \ldots & \mathrm{x}_{1 \mathrm{n}} \\
\mathrm{x}_{21} & \mathrm{x}_{22} & \ldots & \mathrm{x}_{2 \mathrm{n}} \\
\vdots & \vdots & \ldots & \vdots \\
\mathrm{x}_{\mathrm{m} 1} & \mathrm{x}_{\mathrm{m} 2} & \ldots & \mathrm{x}_{\mathrm{mn}}
\end{array}\right]
$$

Eşitlik (1)'de yer alan $x_{i j}$ değerleri, $j$. değerlendirme kriterine göre i. alternatifin aldı ̆̆ 1 değerleri göstermektedir. ( $i$, karar alternatifi sayısı $i=1,2, \ldots, m ; j$ ise değerlendirme kriteri say1s $1=1,2, \ldots, n$ say1s1).

2. Aşama: Karar Matrisinin Normalizasyonu: Karar problemlerinde yer alan farklı birimlere sahip kriterlere ilişkin değerler, normalizasyon işlemiyle [0,1] aralığında değer 
alacak şekilde standart bir hale getirilmelidir. Normalizasyon işlemi Eşitlik (2)'den yararlanılarak gerçekleştirilir.

$$
p_{i j}=\frac{x_{i j}}{\sum_{i=1}^{m} x_{i j}} \quad \forall i, j
$$

Eşitlik (2)'de yer alan $p_{i j}$ değerleri, $j$. değerlendirme kriterine göre $i$. alternatifin aldı̆̆ 1 normalize değeri göstermektedir.

3. Aşama: Kriterlere İlişkin Entropi Değerlerinin Bulunması: Bu aşamada her bir değerlendirme kriterinin Entropi değerleri $\left(e_{j}\right)$, Eşitlik (3)'te gösterilen şekilde hesaplanır.

$$
e_{i j}=-k \cdot \sum_{j=1}^{n} p_{i j} \cdot \ln \left(p_{i j}\right) \mathrm{i}=1,2, \ldots, \mathrm{m} \text { ve } \mathrm{j}=1,2, \ldots, \mathrm{n}
$$

Eşitlik (3)'de yer alan $k$ değeri $k=(\ln (m))^{-1}$ olarak tanımlanan sabit bir katsayıdır ve $0 \leq e_{j} \leq 1$ olacak şekilde değer alır. $e_{j}$ değeri, $j$.kriterin belirsizlik ölçüsü ya da diğer bir ifadeyle Entropi değeri olarak tanımlanır.

4. Aşama: Farklılaşma Derecelerinin Bulunması: Bu aşamada, bir önceki aşamada hesaplanan Entropi değerleri kullanılarak, farklılaşma dereceleri olan $d_{j}$ değerleri her bir kriter için Eşitlik (4)’te gösterilen şekilde hesaplanır.

$$
\mathrm{d}_{\mathrm{j}}=1-\mathrm{e}_{\mathrm{j}} \quad \mathrm{j}=1,2, \ldots, \mathrm{n}
$$

5. Aşama: Entropi Kriter Ağırlıklarının Hesaplanması: Yöntemin son aşamasında her bir kriterin farklılaşma derecesini, toplam farklılaştırma derecesine oranlayarak kriterlerin ağırlık değerleri ( $w_{\mathrm{j}}$ )Eşitlik (5)’te gösterilen şekilde hesaplanır

$$
w_{j}=\frac{d_{j}}{\sum_{j=1}^{n} d_{j}}
$$

Entropi yönteminde kriterlere ilişkin Entropi değerleri hesaplanırken, doğal logaritma fonksiyonu kullanılmaktadır. Karar problemine ilişkin karar matrisinde sıfır ya da negatif değerler olması durumunda, logaritmik hesaplamaların yapılmasında sıkıntı yaşanmaktadır. Bu yüzden negatif veriler için düzeltmeler yapılmalıdır. Bu çalışmada Zhang vd. (2014) tarafindan geliştirilen Z-skoru standartlaştırma dönüşümü kullanılan entropi (improved entropy) yöntemi ile negatif veriler için düzeltmeler yapılmıştır.

$\mathrm{Bu}$ yöntemde önce karar matrisinde yer alan değerler Eşitlik (6)'dan yararlanılarak Zskoru standartlaştırması ile dönüştürülür. 


$$
z_{i j}=\frac{x_{i j}-\bar{X}_{j}}{\sigma_{j}}
$$

Daha sonra Eşitlik (7)'de gösterilen dönüşüm yapılarak karar matrisindeki veriler pozitif hale getirilmiş olur.

$$
z_{i j}^{\prime}=z_{i j}+A ; \quad A>\left|\min z_{i j}\right|
$$

\section{MAIRCA}

MAIRCA (MultiAtributive Ideal-Real Comparative Analysis) yöntemi, Gigovic vd. tarafından literatüre kazandırılan, çok kriterli karar verme yöntemlerinden biridir. MAIRCA yönteminin temeli, ideal ve ampirik derecelendirmeler arasındaki boşlukları tanımlamaya dayalıdır.Her kriter için boşlukların toplanmasıyla, karar alternatifleri için toplam boşlukelde edilir. Süreç sonunda, kriterlerin çoğuna göre ideal derecelendirmelere en yakın değerleri olan alternatif ya da başka bir ifadeyle toplam boşluk değeri en az olan alternatif, en iyi sırayı elde edecektir (Gigovic vd., 2016: 11; Pamucar vd. 2007, 58).

MAIRCA yöntemi sekiz aşamadan oluşan bir uygulama sürecine sahiptir (Pamucar vd., 2018: 1646-1648):

1. Aşama: Başlangıç Karar Matrisinin (X) Oluşturulması:Her bir alternatiften $\left(\mathrm{A}_{\mathrm{i}}\right)$ elde edilen kriter $\left(\mathrm{C}_{\mathrm{j}}\right)$ değerleri Eşitlik (8)'de gösterilmiştir.

$$
\begin{aligned}
& C_{1} \quad C_{2} \quad \ldots \quad C_{n} \\
& {\left[\begin{array}{cccc}
x_{11} & x_{12} & \ldots & x_{1 n} \\
x_{21} & x_{22} & \ldots & x_{2 n} \\
\vdots & \vdots & \ddots & \vdots \\
x_{m 1} & x_{m 2} & \ldots & x_{m n}
\end{array}\right]}
\end{aligned}
$$

X matrisindeki kriterler nitel veya nicel olabilir. Bir alternatifin nicel kriterlerden aldiğ 1 değerler doğrudan yansitılırken, nitel kriterlerin değerleri karar vericilerin öncelikleri ile oluşturulur.

2. Aşama: Alternatiflerin Önceliklerinin Belirlenmesi: Alternatiflerin seçiminde karar vericinin nötr olması demek, önerilen alternatiflerden hiçbirinin bir önceliği olmadığ anlamına gelir. Karar vericinin herhangi bir alternatifi seçimine ilişkin olasılık değerlerinin atanmamış olması, alternatif seçimi sürecinde bir önceliğin olmaması yöntemin bir varsayımıdır. $m$ toplam alternatif sayısı olmak üzere $i$. Alternatifin önceliği $P_{A i}$ Eşitlik (9)'da gösterilen şekilde hesaplanır. 


$$
P_{A i}=\frac{1}{m} ; \quad \sum_{i=1}^{m} P_{A i}=1 \quad i=1,2, \ldots, m
$$

Karar verici her alternatife eşit uzaklıktadır. Bu nedenle bütün öncelikler Eşitlik (10)'da gösterildiği üzere, eşittir.

$$
P_{A 1}=P_{A 2}=\cdots=P_{A m}
$$

3. Aşama: Teorik Derecelendirme Matrisinin ( $\left.T_{p}\right)$ Oluşturulması: $n$ toplam kriter sayıs1, $m$ ise toplam alternatif sayısı olmak üzere $T_{p}$ matrisi $m \times n$ boyutlu bir matristir. Matrisin elemanları $\left(t_{p i j}\right)$, alternatiflerin öncelikleri $\left(P_{A i}\right)$ ile kriter ağırlıklarının $\left(w_{j}\right)$ çarpılması ile hesaplanır.

$$
\begin{aligned}
& \begin{array}{llllllll}
w_{1} & w_{2} & \ldots & w_{n} & w_{1} & w_{2} & \ldots & w_{n}
\end{array} \\
& T_{p}=\left[\begin{array}{cccc}
t_{p 11} & t_{p 12} & \ldots & t_{p 1 n} \\
t_{p 21} & t_{p 22} & \ldots & t_{p 2 n} \\
\vdots & \vdots & \ddots & \vdots \\
t_{p m 1} & t_{p m 2} & \ldots & t_{p m n}
\end{array}\right] \quad\left[\begin{array}{ccccc}
P_{A 1}, w_{1} & P_{A 1}, w_{2} & \ldots & P_{A 1}, w_{n} \\
P_{A 2}, w_{1} & P_{A 2}, w_{2} & \ldots & P_{A 2}, w_{12} \\
\vdots & \vdots & \ddots & \vdots \\
P_{A m}, w_{1} & P_{A m}, w_{2} & \ldots & P_{A m}, w_{n}
\end{array}\right]
\end{aligned}
$$

Bütün alternatiflerin öncelikleri eşit olduğundan $\left(T_{p}\right)$ matrisi satır vektörü olarak Eşitlik (12)'deki gibi gösterilebilir.

$$
\begin{array}{lllllllll}
w_{1} & w_{2} & \ldots & w_{n} & w_{1} & w_{2} & \ldots & w_{n} \\
T_{p}= & {\left[\begin{array}{llllll}
t_{p 1} & t_{p 2} & \ldots & t_{p n}
\end{array}\right]} & {\left[\begin{array}{lllll}
P_{A i}, w_{1} & P_{A i}, w_{2} & \ldots & P_{A i} * w_{n n}
\end{array}\right]}
\end{array}
$$

4. Aşama: Gerçek Derecelendirme Matrisinin $\left(T_{r}\right)$ Tanımlanması: Gerçek derecelendirme matrisinin elemanları Eşitlik (13)’te gösterilmiştir.

$$
\begin{aligned}
& C_{1} \quad C_{2} \quad \ldots \quad C_{n} \\
& T_{r}=\left[\begin{array}{cccc}
t_{r 11} & t_{r 12} & \ldots & t_{r 1 n} \\
t_{r 21} & t_{r 22} & \ldots & t_{r 2 n} \\
\vdots & \vdots & \ddots & \vdots \\
t_{r m 1} & t_{r m 2} & \ldots & t_{r m n}
\end{array}\right]
\end{aligned}
$$

$T_{r}$ matrisinin elde edilebilmesi için teorik derecelendirme matrisi $T_{p}$ ile başlangıç karar matrisi $X$ ' ten faydalanılır.Matris elemanları,kazanç yönlü kriterler için Eşitlik (14), maliyet yönlü kriterler için ise Eşitlik (15)'ten yararlanılarak hesaplanmalıdır. 


$$
\begin{aligned}
& t_{r i j}=t_{p i j} \cdot\left(\frac{x_{i j}-x_{i j}^{-}}{x_{i j}^{+}-x_{i j}^{-}}\right) \\
& t_{r i j}=t_{p i j} \cdot\left(\frac{x_{i j}-x_{i j}^{+}}{x_{i j}^{-}-x_{i j}^{+}}\right)
\end{aligned}
$$

$x_{i j}^{+}$kriterin alternatiften aldı̆̆ en büyük değeri $\left(x_{i j}^{+}=\max \left(x_{1}, x_{2}, \ldots, x_{m}\right)\right), x_{i j}^{-}$ise kriterin alternatiften aldığı en küçük değeri $\left(x_{\bar{i} j}^{-}=\min \left(x_{1}, x_{2}, \ldots, x_{m}\right)\right)$ ifade etmektedir.

5. Aşama: Toplam Boşluk Matrisinin (G) Hesaplanması: Boşluk Matrisi (G), teorik derecelendirme matrisi $\left(T_{p}\right)$ ile gerçek derecelendirme matrisinin $\left(T_{r}\right)$ farkı alınarak Eşitlik (16)-(17)'de gösterilen şekilde hesaplanır.

$$
\begin{gathered}
G=T_{p}-T_{r}=\left[\begin{array}{cccc}
g_{11} & g_{12} & \ldots & g_{1 n} \\
g_{21} & g_{22} & \ldots & g_{2 n} \\
\vdots & \vdots & \ddots & \vdots \\
g_{m 1} & g_{m 2} & \ldots & g_{m n}
\end{array}\right] \\
g_{i j}=t_{p i j}-t_{r i j} g_{i j} \in[0, \infty)
\end{gathered}
$$

6. Aşama: Toplam Boşluğun Alternatifler ile Tanımlanması: Ĕger bir kriter $\left(C_{j}\right)$ için bir alternatifin $\left(A_{i}\right)$ teorik derecesi $\left(t_{p i j}\right)$ ile gerçek derecesi $\left(t_{r i j}\right)$ eşit ve sıfırdan farklı bir değer almışsa, boşluk sıfır olacaktır $\left(g_{i j}=0\right)$. Bu durumda bu kriter $\left(C_{j}\right)$ için bu alternatif $\left(A_{i}\right)$ ideal alternatif $\left(A_{i}^{+}\right)$olacaktır.

Eğer bir kriter $\left(C_{j}\right)$ için bir alternatifin $\left(A_{i}\right)$ teorik derecesi $\left(t_{\text {pij }}\right)$ ile gerçek derecesi ( $\left.t_{r i j}\right)$ sıfira eşitse $\left(t_{p i j}=t_{r i j}=g_{i j}=0\right)$. Bu durumda bu kriter $\left(C_{j}\right)$ için bu alternatif $\left(A_{i}\right)$ en kötü alternatif $\left(A_{i}^{-}\right)$olacaktır.

7. Aşama: Alternatiflerin Nihai Kriter Fonksiyonlarının Değerinin $\left(Q_{i}\right)$ Hesaplanması : Kriter fonksiyonlarının değeri, her bir alternatif için boşluk matrisinin $(G)$ satırları toplanarak Eşitlik (18)'de gösterilen şekilde hesaplanır.

$$
Q_{i}=\sum_{j=1}^{n} g_{i j}, \quad i=1,2, \ldots, m
$$

8. Aşama: En Iyi Alternatifin Seçimi Alternatifler nihai kriter fonksiyon değerlerine göre sıralanır. En küçük nihai kriter fonksiyon değerine sahip olan alternatif en iyi alternatif olarak belirlenir. 


\section{UYGULAMA}

Çalışmada BIST Ticaret Endeksinde (XTCRT) yer alan firmaların finansal performanslarının ÇKKV karar verme yöntemleri ile değerlendirilmesi amaçlanmıştır. Bu endekste yer alan işletmeler Tablo 1'de gösterilmektedir.

Tablo 1. BIST Ticaret Endeksinde Yer Alan Firmalar

\begin{tabular}{|c|c|}
\hline BIST Kodu & 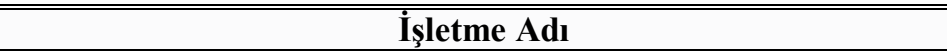 \\
\hline 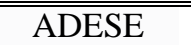 & 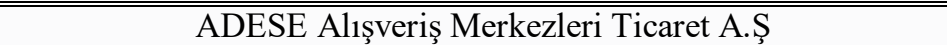 \\
\hline BIMAS & BìM Birleşik Mağazalar A.Ş \\
\hline BIZIM & BİZİM Toptan Satıș Mağazaları A.Ş \\
\hline CRFSA & CARREFOURSA Sabancı Ticaret Merkezi A.Ş. \\
\hline DOAS & DOĞUŞ Otomotiv Servis ve Ticaret A.Ş. \\
\hline INTEM & İNTEMA İnşaat ve Tesisat Malzemeleri Yatırım ve Pazarlama A.Ş \\
\hline MAVI & MAVİ Giyim Sanayi ve Ticaret A.Ş. \\
\hline MEPET & MEPET Metro Petrol ve Tesisleri Sanayi Ticaret A.Ș. \\
\hline MGROS & MIGGROS Ticaret A.Ş. \\
\hline MIPAZ & MİLPA Ticari ve Sinai Ürünler Pazarlama Sanayi ve Ticaret A.Ş. \\
\hline PSDTC & PERGAMON STATUS Diş Ticaret A.Ş. \\
\hline SANKO & SANKO Pazarlama İthalat İhracat A.Ş. \\
\hline$\overline{\text { SELEC }}$ & SELÇUK Ecza Deposu Ticaret ve Sanayi A.Ș. \\
\hline SOKM & Ş̧OK Marketler Ticaret A.Ş. \\
\hline TKNSA & TEKNOSA İç ve Dış Ticaret A.Ş. \\
\hline TGSAS & TGS Diş Ticaret A.Ş \\
\hline VAKKO & VAKKO Tekstil ve Hazır Giyim Sanayi İşletmeleri A.Ş. \\
\hline
\end{tabular}

Kaynak: https://www.kap.org.tr/tr/Endeksler

Finansal oranlar, bir diğer değişle rasyolar finansal analiz işlemlerindekullanılan, bir işletmenin bilançosunun hesaplarının yatay ve dikey olarak incelenmesini ve bilanço kalemleri arasında çeşitli ilişkiler kurulmasını sağlayan oranlardır (Sarıkamış, 2007, s.44).

Finansal performansın değerlendirilmesi çalışma kapsamında yer alan kriterler temel finansal oranlardan en fazla kullanılan ve ticaret işletmeleri için uygun olduğu düşünülen, cari oran, asit test oranı, nakit oranı, aktif devir hızı, kaldıraç oranı, aktif karlılığı özsermaye karlılı̆̆1 ve net dönem karındaki büyüme olarak belirlenmiştir. Belirlenen kriterlere ilişkin tanımlamalar ise Tablo 2'de gösterilmiştir.

Tablo 2. Finansal Performans Değerlendirme Kriterleri ve Tanımlamalar

\begin{tabular}{|ll||}
\hline \hline Kriter & \multicolumn{1}{c||}{ Tanımlama } \\
\hline \hline K1 Cari Oran & Dönen Varlıklar/Kısa Vadeli Yabancı Kaynaklar(KVYK) \\
\hline K2 Asit Test Oranı & (Dönen Varlıklar-Stoklar)/ KVYK \\
\hline K3 Nakit Oranı & Hazır Değerler/ KVYK \\
\hline K4 Aktif Devir Hızı & Net Satı̧̧lar/Toplam Aktifler \\
\hline \hline K5 Finansal Kaldıraç Oranı & Toplam Yabancı Kaynaklar/Toplam Aktifler \\
\hline K6 Aktif Karlıı̆ıı & Net Kar/Toplam Aktifler \\
\hline \hline K7 Özsermaye Karlı̆ı̆ı & Net Kar/Özsermaye \\
\hline $\begin{array}{l}\text { K8 Net Dönem Karındaki } \\
\text { Büyüme }\end{array}$ & (Net Dönem Karı - Önceki Dönem Net Karı)/Önceki Dönem Net Karı \\
\hline
\end{tabular}


Cari oran, kısa vadeli borçların karşılanma performansını değerlendirmek için seçilmiş olan likidite oranlarından biridir. Oranın 1'den büyük olması işletmenin kısa vadeli borçlarını ödeme konusunda sıkıntı yaşamadığ 1 anlamını taşımaktadır. Asit test oranı dönen varlıkların içinden likiditesi düşük olan stokların çıkarılması sonucu elde kalan aktiflerin kısa vadeli borçları ödeme yeterliliğini ortaya koymakta iken; nakit oranı, işletmenin elindeki en likit hazır değerlerin kısa vadeli borçlarının ne kadarını karşıladığını göstermektedir. Likiditesi yüksek olan işletme yatırımcı için de cazip alternatif olarak görülmektedir. Finansal kaldıraç oranı işletmenin varlıklarının ne kadarının yabancı kaynak kullanımı ile finanse edildiğini gösteren bir orandır ve bu oranın düşük olması tercih edilir. İşletmenin karlılık durumu hakkında bilgi veren karlılık oranlarının ise yüksek olması olumlu bir gösterge olarak yorumlanır.

BIST ticaret endeksinde yer alan on yedi firmanın 2018 y1lü̈çüncü üç aylıkfinansal tabloları dikkate alınarak, her kriter için ilgili değerler hesaplanmış ve karar matrisi Tablo 3 'te gösterilmiştir.

Tablo 3. Karar Matrisi

\begin{tabular}{|llllllllr||}
\hline \hline İşletme/Kriter & K1 & K2 & K3 & K4 & K5 & K6 & K7 & \multicolumn{1}{c|}{ K8 } \\
\hline \hline ADESE & 0.840 & 0.527 & 0.038 & 0.469 & 0.501 & 0.011 & 0.023 & -3.572 \\
\hline \hline BIMAS & 0.908 & 0.522 & 0.161 & 2.762 & 0.623 & 0.106 & 0.281 & 0.390 \\
\hline \hline BIZIM & 0.957 & 0.535 & 0.261 & 3.274 & 0.859 & 0.018 & 0.126 & 1.482 \\
\hline \hline CRFSA & 0.621 & 0.351 & 0.210 & 1.271 & 0.905 & 0.069 & 0.725 & 2.531 \\
\hline \hline DOAS & 0.896 & 0.192 & 0.029 & 1.198 & 0.796 & 0.020 & 0.098 & -0.084 \\
\hline \hline INTEM & 0.933 & 0.899 & 0.004 & 1.383 & 0.999 & -0.044 & -71.393 & -1.198 \\
\hline \hline MAVI & 1.068 & 0.612 & 0.296 & 1.267 & 0.761 & 0.072 & 0.301 & 0.204 \\
\hline \hline MEPET & 0.430 & 0.364 & 0.036 & 0.884 & 0.481 & -0.006 & -0.011 & -1.163 \\
\hline \hline MGROS & 0.669 & 0.357 & 0.300 & 1.275 & 0.976 & -0.110 & -4.628 & -2.671 \\
\hline MIPAZ & 0.218 & 0.096 & 0.021 & 0.058 & 0.203 & -0.037 & -0.046 & 0.404 \\
\hline \hline PSDTC & 1.051 & 1.051 & 0.170 & 0.006 & 0.952 & 0.021 & 0.428 & 2.710 \\
\hline SANKO & 3.602 & 3.557 & 0.773 & 1.561 & 0.248 & 0.043 & 0.057 & -0.086 \\
\hline \hline SELEC & 1.428 & 1.137 & 0.118 & 1.512 & 0.637 & 0.045 & 0.123 & 0.199 \\
\hline SOKM & 0.432 & 0.160 & 0.082 & 2.901 & 0.896 & 0.041 & 0.390 & 1.393 \\
\hline \hline TKNSA & 0.749 & 0.183 & 0.044 & 3.148 & 1.064 & -0.012 & 0.190 & -1.571 \\
\hline \hline TGSAS & 1.012 & 0.947 & 0.002 & 0.004 & 0.987 & 0.002 & 0.151 & 1.956 \\
\hline \hline VAKKO & 1.209 & 0.506 & 0.142 & 0.838 & 0.694 & 0.046 & 0.150 & 5.195 \\
\hline \hline
\end{tabular}

Karar matrisindeki değerler düzenlendikten sonra, Eşitlik (2)'den yararlanılarak Tablo 3 'te gösterilen karar matrisi normalize edilir. Normalize edilen karar matrisi Tablo 4'te gösterilmektedir.

Tablo 4.Normalize Karar Matrisi

\begin{tabular}{|lrrrrrrrr||}
\hline \hline İşletme/Kriter & K1 & K2 & K3 & K4 & K5 & K6 & K7 & K8 \\
\hline \hline ADESE & 0.049 & 0.044 & 0.014 & 0.020 & 0.040 & 0.056 & 0.063 & 0.000 \\
\hline \hline BIMAS & 0.053 & 0.043 & 0.060 & 0.116 & 0.050 & 0.100 & 0.063 & 0.059 \\
\hline \hline BIZIM & 0.056 & 0.045 & 0.097 & 0.137 & 0.068 & 0.059 & 0.063 & 0.076 \\
\hline \hline CRFSA & 0.036 & 0.029 & 0.078 & 0.053 & 0.072 & 0.083 & 0.063 & 0.091 \\
\hline \hline DOAS & 0.053 & 0.016 & 0.011 & 0.050 & 0.063 & 0.060 & 0.063 & 0.052 \\
\hline \hline INTEM & 0.055 & 0.075 & 0.002 & 0.058 & 0.079 & 0.031 & 0.000 & 0.036 \\
\hline
\end{tabular}


Muhasebe ve Finansman Dergisi - Ocak/2020

(85): 287-312

\begin{tabular}{|lllllllll||}
\hline MAVI & 0.063 & 0.051 & 0.110 & 0.053 & 0.060 & 0.084 & 0.063 & 0.056 \\
\hline \hline MEPET & 0.025 & 0.030 & 0.013 & 0.037 & 0.038 & 0.049 & 0.063 & 0.036 \\
\hline \hline MGROS & 0.039 & 0.030 & 0.112 & 0.054 & 0.078 & 0.000 & 0.059 & 0.014 \\
\hline \hline MIPAZ & 0.013 & 0.008 & 0.008 & 0.002 & 0.016 & 0.034 & 0.063 & 0.059 \\
\hline \hline PSDTC & 0.062 & 0.088 & 0.063 & 0.000 & 0.076 & 0.061 & 0.063 & 0.094 \\
\hline \hline SANKO & 0.212 & 0.297 & 0.288 & 0.066 & 0.020 & 0.071 & 0.063 & 0.052 \\
\hline \hline SELEC & 0.084 & 0.095 & 0.044 & 0.064 & 0.051 & 0.072 & 0.063 & 0.056 \\
\hline \hline SOKM & 0.025 & 0.013 & 0.031 & 0.122 & 0.071 & 0.070 & 0.063 & 0.074 \\
\hline \hline TKNSA & 0.044 & 0.015 & 0.016 & 0.132 & 0.085 & 0.046 & 0.063 & 0.030 \\
\hline \hline TGSAS & 0.059 & 0.079 & 0.001 & 0.000 & 0.078 & 0.052 & 0.063 & 0.083 \\
\hline \hline VAKKO & 0.071 & 0.042 & 0.053 & 0.035 & 0.055 & 0.072 & 0.063 & 0.131 \\
\hline
\end{tabular}

Eşitlik (3) ve (4)'ten faydalanılarak kriterlere ilişkin entropi değerleri ve farklılaşma değerleri hesaplanmış, ardından Eşitlik (5) yardımıyla entropi ağırlıkları bulunmuştur. Uygulama adımlarına ilişkin sonuçlar Tablo 5’te gösterilmiştir.

Tablo 5.Entropi Değerleri ve Kriter Ağırlıkları

\begin{tabular}{|lcccccccc|}
\hline İșletme/Kriter & K1 & K2 & K3 & K4 & K5 & K6 & K7 & K8 \\
\hline ADESE & -0.148 & -0.137 & -0.060 & -0.077 & -0.128 & -0.162 & -0.173 & -0.002 \\
\hline \hline BIMAS & -0.156 & -0.136 & -0.169 & -0.250 & -0.149 & -0.230 & -0.174 & -0.167 \\
\hline \hline BIZIM & -0.162 & -0.139 & -0.227 & -0.273 & -0.183 & -0.167 & -0.174 & -0.195 \\
\hline \hline CRFSA & -0.121 & -0.103 & -0.199 & -0.156 & -0.189 & -0.206 & -0.175 & -0.218 \\
\hline DOAS & -0.155 & -0.066 & -0.049 & -0.150 & -0.175 & -0.170 & -0.174 & -0.154 \\
\hline \hline INTEM & -0.159 & -0.194 & -0.010 & -0.165 & -0.201 & -0.108 & -0.001 & -0.119 \\
\hline \hline MAVI & -0.174 & -0.152 & -0.243 & -0.156 & -0.170 & -0.209 & -0.174 & -0.162 \\
\hline MEPET & -0.093 & -0.106 & -0.057 & -0.122 & -0.125 & -0.147 & -0.173 & -0.120 \\
\hline MGROS & -0.127 & -0.105 & -0.245 & -0.157 & -0.198 & -0.001 & -0.166 & -0.059 \\
\hline \hline MIPAZ & -0.056 & -0.039 & -0.038 & -0.015 & -0.066 & -0.115 & -0.173 & -0.168 \\
\hline \hline PSDTC & -0.172 & -0.213 & -0.174 & -0.002 & -0.195 & -0.170 & -0.174 & -0.222 \\
\hline \hline SANKO & -0.329 & -0.360 & -0.358 & -0.179 & -0.077 & -0.187 & -0.174 & -0.154 \\
\hline SELEC & -0.208 & -0.223 & -0.137 & -0.175 & -0.151 & -0.189 & -0.174 & -0.162 \\
\hline \hline SOKM & -0.093 & -0.058 & -0.107 & -0.256 & -0.188 & -0.186 & -0.174 & -0.193 \\
\hline TKNSA & -0.137 & -0.064 & -0.067 & -0.268 & -0.209 & -0.141 & -0.174 & -0.105 \\
\hline \hline TGSAS & -0.168 & -0.200 & -0.005 & -0.002 & -0.200 & -0.154 & -0.174 & -0.206 \\
\hline VAKKO & -0.188 & -0.134 & -0.155 & -0.118 & -0.160 & -0.190 & -0.174 & -0.266 \\
\hline TOPLAM & $\mathbf{- 2 . 6 4 6}$ & $\mathbf{- 2 . 4 3 0}$ & $\mathbf{- 2 . 3 0 2}$ & $\mathbf{- 2 . 5 2 1}$ & $\mathbf{- 2 . 7 6 5}$ & $\mathbf{- 2 . 7 3 2}$ & $\mathbf{- 2 . 7 7 3}$ & $\mathbf{- 2 . 6 7 3}$ \\
\hline \hline ej & 0.9339 & 0.8576 & 0.8124 & 0.8898 & 0.9760 & 0.9643 & 0.9789 & 0.9436 \\
\hline \hline dj & 0.0661 & 0.1424 & 0.1876 & 0.1102 & 0.0240 & 0.0357 & 0.0211 & 0.0564 \\
\hline wj & $\mathbf{0 . 1 0 2 8}$ & $\mathbf{0 . 2 2 1 3}$ & $\mathbf{0 . 2 9 1 5}$ & $\mathbf{0 . 1 7 1 2}$ & $\mathbf{0 . 0 3 7 3}$ & $\mathbf{0 . 0 5 5 5}$ & $\mathbf{0 . 0 3 2 8}$ & $\mathbf{0 . 0 8 7 6}$ \\
\hline
\end{tabular}

Entropi yöntemi ile belirlenen kriter ağırlıklarına göre en önemli finansal performans kriterlerinin sırasıyla nakit oranı, asit test oranı ve aktif devir hızı iken, en az önemli kriterlerin özsermaye karlılığı, kaldıraç oranı ve aktif karlılığı olduğu görülmektedir (Tablo 5). Kriterlerin önem ağırlıklarının belirlenmesinin ardından MAIRCA yöntemi ile işletmelerin finansal performans sıralamalarının elde edilmesi için ilk olarak Eşitlik (9) yardımıyla 
alternatiflerin öncelik değerleri (PAi) belirlenmiştir. Sonrasında ise Eşitlik (11)'den yararlanılarak teorik derecelendirme matrisi (Tp) Tablo 6'da gösterilen şekilde elde edilmiştir.

Tablo 6.Teorik Derecelendirme Matrisi (Tp)

\begin{tabular}{|lccccccccc|}
\hline İşletme/Kriter & K1 & K2 & K3 & K4 & K5 & K6 & K7 & K8 & P $_{\text {Ai }}$ \\
\hline \hline ADESE & 0.0051 & 0.0069 & 0.0007 & 0.0047 & 0.0011 & 0.0079 & 0.0080 & 0.0000 & 0.0588 \\
\hline BIMAS & 0.0055 & 0.0068 & 0.0028 & 0.0278 & 0.0014 & 0.0140 & 0.0080 & 0.0097 & 0.0588 \\
\hline \hline BIZIM & 0.0058 & 0.0070 & 0.0045 & 0.0330 & 0.0019 & 0.0083 & 0.0080 & 0.0123 & 0.0588 \\
\hline \hline CRFSA & 0.0038 & 0.0046 & 0.0036 & 0.0128 & 0.0020 & 0.0116 & 0.0080 & 0.0149 & 0.0588 \\
\hline \hline DOAS & 0.0054 & 0.0025 & 0.0005 & 0.0121 & 0.0017 & 0.0084 & 0.0080 & 0.0085 & 0.0588 \\
\hline \hline INTEM & 0.0056 & 0.0117 & 0.0001 & 0.0139 & 0.0022 & 0.0043 & 0.0000 & 0.0058 & 0.0588 \\
\hline \hline MAVI & 0.0065 & 0.0080 & 0.0051 & 0.0128 & 0.0017 & 0.0118 & 0.0080 & 0.0092 & 0.0588 \\
\hline \hline MEPET & 0.0026 & 0.0047 & 0.0006 & 0.0089 & 0.0011 & 0.0068 & 0.0080 & 0.0059 & 0.0588 \\
\hline \hline MGROS & 0.0040 & 0.0046 & 0.0051 & 0.0128 & 0.0021 & 0.0000 & 0.0075 & 0.0022 & 0.0588 \\
\hline MIPAZ & 0.0013 & 0.0013 & 0.0004 & 0.0006 & 0.0004 & 0.0048 & 0.0080 & 0.0097 & 0.0588 \\
\hline \hline PSDTC & 0.0064 & 0.0137 & 0.0029 & 0.0001 & 0.0021 & 0.0085 & 0.0080 & 0.0153 & 0.0588 \\
\hline \hline SANKO & 0.0218 & 0.0463 & 0.0133 & 0.0157 & 0.0005 & 0.0099 & 0.0080 & 0.0085 & 0.0588 \\
\hline \hline SELEC & 0.0086 & 0.0148 & 0.0020 & 0.0152 & 0.0014 & 0.0100 & 0.0080 & 0.0092 & 0.0588 \\
\hline \hline SOKM & 0.0026 & 0.0021 & 0.0014 & 0.0292 & 0.0020 & 0.0098 & 0.0080 & 0.0121 & 0.0588 \\
\hline \hline TKNSA & 0.0045 & 0.0024 & 0.0007 & 0.0317 & 0.0023 & 0.0064 & 0.0080 & 0.0049 & 0.0588 \\
\hline \hline TGSAS & 0.0061 & 0.0123 & 0.0000 & 0.0000 & 0.0022 & 0.0073 & 0.0080 & 0.0135 & 0.0588 \\
\hline \hline VAKKO & 0.0073 & 0.0066 & 0.0024 & 0.0084 & 0.0015 & 0.0101 & 0.0080 & 0.0213 & 0.0588 \\
\hline
\end{tabular}

Teorik derecelendirme matrisinin Eşitlik 14 ve 15 'te verilen hesaplamalar ile normalize edilmesi ile ise gerçek derecelendirme matrisi ( $\mathrm{Tg}$ ) Tablo 7'de gösterilen şekilde oluşturulmuştur.

Tablo 7.Gerçek Derecelendirme Matrisi (Tg)

\begin{tabular}{||lcccccccc||}
\hline \hline İşletme/Kriter & K1 & K2 & K3 & K4 & K5 & K6 & K7 & K8 \\
\hline \hline ADESE & 0.0009 & 0.0009 & 0.0000 & 0.0007 & 0.0007 & 0.0044 & 0.0079 & 0.0000 \\
\hline \hline BIMAS & 0.0011 & 0.0008 & 0.0006 & 0.0235 & 0.0007 & 0.0140 & 0.0080 & 0.0044 \\
\hline \hline BIZIM & 0.0013 & 0.0009 & 0.0015 & 0.0330 & 0.0004 & 0.0049 & 0.0079 & 0.0071 \\
\hline \hline CRFSA & 0.0004 & 0.0003 & 0.0010 & 0.0050 & 0.0004 & 0.0096 & 0.0080 & 0.0103 \\
\hline DOAS & 0.0011 & 0.0001 & 0.0000 & 0.0044 & 0.0005 & 0.0051 & 0.0079 & 0.0034 \\
\hline \hline INTEM & 0.0012 & 0.0027 & 0.0000 & 0.0059 & 0.0002 & 0.0013 & 0.0000 & 0.0016 \\
\hline \hline MAVI & 0.0016 & 0.0012 & 0.0019 & 0.0049 & 0.0006 & 0.0100 & 0.0080 & 0.0040 \\
\hline \hline MEPET & 0.0002 & 0.0004 & 0.0000 & 0.0024 & 0.0007 & 0.0033 & 0.0079 & 0.0016 \\
\hline MGROS & 0.0005 & 0.0004 & 0.0020 & 0.0050 & 0.0002 & 0.0000 & 0.0069 & 0.0002 \\
\hline \hline MIPAZ & 0.0000 & 0.0000 & 0.0000 & 0.0000 & 0.0004 & 0.0016 & 0.0079 & 0.0044 \\
\hline PSDTC & 0.0016 & 0.0038 & 0.0006 & 0.0000 & 0.0003 & 0.0051 & 0.0080 & 0.0110 \\
\hline \hline SANKO & 0.0218 & 0.0463 & 0.0133 & 0.0075 & 0.0005 & 0.0070 & 0.0079 & 0.0034 \\
\hline SELEC & 0.0031 & 0.0044 & 0.0003 & 0.0070 & 0.0007 & 0.0072 & 0.0079 & 0.0040 \\
\hline \hline SOKM & 0.0002 & 0.0000 & 0.0001 & 0.0259 & 0.0004 & 0.0068 & 0.0080 & 0.0069 \\
\hline \hline TKNSA & 0.0007 & 0.0001 & 0.0000 & 0.0305 & 0.0000 & 0.0029 & 0.0079 & 0.0011 \\
\hline \hline TGSAS & 0.0014 & 0.0030 & 0.0000 & 0.0000 & 0.0002 & 0.0038 & 0.0079 & 0.0085 \\
\hline VAKKO & 0.0021 & 0.0008 & 0.0004 & 0.0022 & 0.0007 & 0.0073 & 0.0079 & 0.0213 \\
\hline \hline
\end{tabular}

Teorik dereceler ile gerçek derecelerin farkının alınmasıyla boşluk matrisi elde Tablo 8'de gösterilmiştir. Boşluk derecelerine göre likidite oranları (K1, K2, K3) açısından en iyi 
alternatifin SANKO Holding, aktif devir hızı kriteri (K4) açısından en iyi alternatifin BIZIM A.Ş., finansal kaldıraç kriteri (K5) açısından en iyi alternatifin MİLPA, aktif karlılığ açısından in iyi işletme BIM A.Ş. iken, özsermaye karlılığı açısından CARREFOURSA A.Ş. en iyi performansı göstermektedir. VAKKO ise K8 net dönem karındaki büyüme oranı ile bu kriterin en iyi alternatifi olmuştur.

Tablo 8.Boşluk Matrisi (G)

\begin{tabular}{|lcccccccc||}
\hline \hline İsletme/Kriter & K1 & K2 & K3 & K4 & K5 & K6 & K7 & K8 \\
\hline \hline ADESE & 0.00414 & 0.00601 & 0.00062 & 0.00405 & 0.00038 & 0.00345 & 0.00008 & 0.00004 \\
\hline \hline BIMAS & 0.00437 & 0.00596 & 0.00219 & 0.00436 & 0.00067 & $\mathbf{0 . 0 0 0 0 0}$ & 0.00005 & 0.00529 \\
\hline \hline BIZIM & 0.00452 & 0.00608 & 0.00297 & $\mathbf{0 . 0 0 0 0 0}$ & 0.00144 & 0.00338 & 0.00007 & 0.00521 \\
\hline \hline CRFSA & 0.00331 & 0.00424 & 0.00263 & 0.00784 & 0.00162 & 0.00200 & $\mathbf{0 . 0 0 0 0 0}$ & 0.00452 \\
\hline DOAS & 0.00433 & 0.00243 & 0.00049 & 0.00766 & 0.00120 & 0.00335 & 0.00007 & 0.00512 \\
\hline \hline INTEM & 0.00445 & 0.00898 & 0.00007 & 0.00805 & 0.00203 & 0.00299 & 0.00002 & 0.00423 \\
\hline \hline MAVI & 0.00483 & 0.00678 & 0.00314 & 0.00783 & 0.00108 & 0.00185 & 0.00005 & 0.00524 \\
\hline \hline MEPET & 0.00243 & 0.00437 & 0.00059 & 0.00651 & 0.00034 & 0.00350 & 0.00008 & 0.00427 \\
\hline \hline MGROS & 0.00351 & 0.00430 & 0.00316 & 0.00785 & 0.00192 & 0.00002 & 0.00055 & 0.00200 \\
\hline \hline MIPAZ & 0.00131 & 0.00126 & 0.00036 & 0.00057 & $\mathbf{0 . 0 0 0 0 0}$ & 0.00315 & 0.00009 & 0.00530 \\
\hline PSDTC & 0.00479 & 0.00991 & 0.00228 & 0.00006 & 0.00182 & 0.00334 & 0.00003 & 0.00434 \\
\hline \hline SANKO & $\mathbf{0 . 0 0 0 0 0}$ & $\mathbf{0 . 0 0 0 0 0}$ & $\mathbf{0 . 0 0 0 0 0}$ & 0.00823 & 0.00003 & 0.00290 & 0.00007 & 0.00512 \\
\hline \hline SELEC & 0.00554 & 0.01035 & 0.00171 & 0.00820 & 0.00071 & 0.00284 & 0.00007 & 0.00524 \\
\hline \hline SOKM & 0.00244 & 0.00204 & 0.00127 & 0.00333 & 0.00158 & 0.00295 & 0.00004 & 0.00525 \\
\hline \hline TKNSA & 0.00382 & 0.00232 & 0.00071 & 0.00122 & 0.00234 & 0.00347 & 0.00006 & 0.00378 \\
\hline \hline TGSAS & 0.00468 & 0.00929 & 0.00003 & 0.00004 & 0.00197 & 0.00350 & 0.00006 & 0.00498 \\
\hline \hline VAKKO & 0.00517 & 0.00581 & 0.00199 & 0.00629 & 0.00087 & 0.00281 & 0.00006 & $\mathbf{0 . 0 0 0 0 0}$ \\
\hline
\end{tabular}

Boşluk matrisindeki değerler ve Eşitlik (18)'den yararlanılarak her bir işletme için nihai kriter fonksiyon değerleri (Qi) hesaplanarak, finansal performans sıralaması Tablo 9'da gösterilen şekilde elde edilmiştir.

Tablo 9.Nihai Kriter Fonksiyon Değerleri (Qi) ve Siralamalar

\begin{tabular}{|lcr||}
\hline İşletmeler & \multicolumn{1}{c}{ Qi } & \multicolumn{1}{c|}{ Siralama } \\
\hline \hline ADESE & 0.01876 & 4 \\
\hline \hline BIMAS & 0.02288 & 7 \\
\hline \hline BIZIM & 0.02367 & 10 \\
\hline \hline CRFSA & 0.02615 & 13 \\
\hline \hline DOAS & 0.02465 & 12 \\
\hline \hline INTEM & 0.03083 & 16 \\
\hline \hline MAVI & 0.03080 & 15 \\
\hline \hline MEPET & 0.02209 & 6 \\
\hline \hline MGROS & 0.02330 & 9 \\
\hline \hline MIPAZ & $\mathbf{0 . 0 1 2 0 3}$ & $\mathbf{1}$ \\
\hline \hline PSDTC & 0.02657 & 14 \\
\hline \hline SANKO & $\mathbf{0 . 0 1 6 3 6}$ & $\mathbf{2}$ \\
\hline \hline SELEC & 0.03466 & 17 \\
\hline \hline SOKM & 0.01890 & 5 \\
\hline \hline TKNSA & $\mathbf{0 . 0 1 7 7 1}$ & $\mathbf{3}$ \\
\hline \hline TGSAS & 0.02456 & 11 \\
\hline \hline VAKKO & 0.02299 & 8 \\
\hline \hline
\end{tabular}




\section{SONUÇ}

$\mathrm{Bu}$ çalışmada işletme performansının en önemli göstergelerinden biri olan finansal performansın ÇKKV yöntemleri kullanılarak değerlendirilmesi hedeflenmiştir. Bu doğrultuda uygulama alanı olarak belirlenen BIST Ticaret endeksinde yer alan işletmelerin finansal performansları analiz edilmiştir.

Finansal performansanalizinde dikkate alınan kriterler temel finansal oranlardan en fazla kullanılan ve ticaret işletmeleri için uygun olduğu düşünülen, cari oran, asit test oranı, nakit oranı, aktif devir hızı, kaldıraç oranı, aktif karlılığı özsermaye karlılığı ve net dönem karındaki büyüme olarak belirlenmiştir. Belirlenen bu kriterlere ilişkin kriter ağırlıkları objektif bir yöntem olan Entropi ile hesaplanmıştır. Entropi yöntemiyle elde edilen sonuçlara göre, en önemli kriterlerin sırasıyla nakit oranı, asit test oranı ve aktif devir hızı olduğu; en az önemli kriterlerin isesırasıyla özsermaye karlılığ belirlenmiştir. Entropi yöntemiyle kriter ağırlıkları hesaplandıktan sonra, MAIRCA yöntemiyle işletmelerin finansal performans sıralamalarının elde edilmiştir. Elde edilen sonuçlara göre finansal performansı en yüksek olan işletmelerin sırasıyla, MILPA Ticari ve Sinai Ürünler Pazarlama Sanayi ve Ticaret A.Ş., SANKO Pazarlama İthalat İhracat A.Ş. ve TEKNOSA İç ve Dış Ticaret A.Ş. olduğu tespit edilmiştir.

BIST ticaret endeksindeki işletmelerin finansal performanslarının değerlendirildiği mevcut çalışmada kullanılan MAIRCA yöntemi, çalışmanın yapıldığ 1 tarih itibariyle ulusal literatürde yer almamaktadır. Dolayısıyla bu çalışma ile MAIRCA yönteminin ulusal literatüre tanıtılması hedeflenmiştir. Uygulama bulguları, çok kriterli bir değerlendirme süreci olan finansal performans ölçümünde MAIRCA yönteminin kullanılabilir bir yöntem olduğunu göstermiştir. Gelecek çalışmalarda MAIRCA yöntemi gerek tek başına gerekse de diğer ÇKKV yöntemleri ile bütünleşik olarak ele alınarak, farklı sektörlerde uygulamalar gerçekleştirilebilir.

\section{KAYNAKLAR}

Akçakanat, Özen - Eren, Hande - Aksoy, Esra - Ömürbek, Vesile (2017), "Bankacılık Sektöründe Entropi ve WASPAS Yöntemleri İle Performans Değerlendirmesi”, Süleyman Demirel Üniversitesi İktisadi ve İdari Bilimler Fakültesi Dergisi, 22(2), ss. 285-300.

Akhisar, Ilyas (2014), "Performance Ranking of Turkish Insurance Companies: The ANP Application",Finansal Araştırmalar ve Çalışmalar Dergisi, 6(11), pp. 1-13.

Akyüz, Y1lmaz - Bozdoğan, Tunga - Hantekin, Emin (2011), “TOPSIS Yöntemiyle Finansal Performansın Değerlendirilmesi ve Bir Uygulama”, Afyon Kocatepe Üniversitesi, İ̇BF Dergisi, 13(1): ss. 73-92.

Atukalp, M. Esra (2019), “Borsa İstanbul'da işlem Gören Çimento Firmalarının Finansal Performansının Analizi”, Muhasebe ve Finansman Dergisi, 81, ss. 213- 230.

Ayçin, Ejder (2018), “BIST Menkul Kıymet Yatırım Ortaklıkları Endeksinde (XYORT) Yer Alan İşletmelerin Finansal Performanslarının Entropi Ve Gri İlişkisel Analiz 
Bütünleşik Yaklaşımı ile Değerlendirilmesi”, Dokuz Eylül Üniversitesi İktisadi ve İdari Bilimler Fakültesi Dergisi, 33(2), ss. 595-622

Aytekin, Ahmet - Karamaşa, Çağlar (2017), “Analyzing Financial Performance of Insurance Companies Traded in BIST via Fuzzy Shannon's Entropy Based Fuzzy TOPSIS Methodology", Alphanumeric Journal, 5(1), ss. 51-84.

Baležentis, Alvydas - Baležentis, Tomas - Misiūnas, Algimantas (2012), “An Integrated Assessment of Lithuanian Economic Sectors Based on Financial Ratios and Fuzzy MCDM Methods", Technological and Economic Development of Economy, 18(1), pp. 34-53.

Bölükbaş, Ufuk - Çelik, Erkan - Güneri, Ali Fuat (2012), "Performance Evaluation of Turkish Retail Firms Using the Fuzzy AHP, PROMETHEE, ELECTRE and VIKOR methods", Uncertainty Modelling in Knowledge Engineering and Decision Making, pp.243-248.

Bülbül, Serpil - Köse, Ali (2011), “Türk Gıda Şirketlerinin Finansal Performansının Çok Amaçlı Karar Verme Yöntemleriyle Değerlendirilmesi”, Atatürk Üniversitesi İktisadi ve İdari Bilimler Dergisi 10. Ekonometri ve İstatistik Sempozyumu Özel Sayısı, ss. 71-97.

Bulgurcu, Berna. (2012), “Application of TOPSIS Technique for Financial Performance Evaluation of Technology Firms in Istanbul Stock Exchange Market", Procedia Social and Behavioral Sciences, 62, pp. 1033 - 1040.

Çelen, Aydın. (2014), "Evaluating the Financial Performance of Turkish Banking Sector: A Fuzzy MCDM Approach. Journal of Economic Cooperation and Development”, 35(2), pp. 43-70.

Chang, Shun-Chiao - Tsai, Pei-Hsuan (2016), “A Hybrid Financial Performance Evaluation Model for Wealth Management Banks Following the Global Financial Crisis", Technological and Economic Development of Economy, 22(1), pp. 21-46.

Dinçer, Hasan -Hacığlu, Ümit - Yüksel, Serhat (2017), “Balanced Scorecard Based Performance Measurement of European airlines Using A Hybrid Multicriteria Decision Making Approach Under the Fuzzy Environment”, Journal of Air Transport Management, 63, pp. 17-33.

Doğan, Mesut (2013), "Measuring Bank Performance with Gray Relational Analysis: The Case of Turkey", Ege Akademik Bakış, 13(2), pp. 215-225.

Dong, Jiu-Ying - Chen, Yang -Wan, Shu-Ping (2018). “A Cosine Similarity Based QUALIFLEX Approach with Hesitant Fuzzy Linguistic Term Sets for Financial Performance Evaluation", Applied Soft Computing, 69, pp. 316-329.

Ecer, Fatih - Günay, Fatih (2014), "Borsa İstanbul'da İşlem Gören Turizm Şirketlerinin Finansal Performanslarının Gri İlişkisel Analiz Yöntemiyle Ölçülmesi”. Anatolia: Turizm Araştırmaları Dergisi, 25(1), ss. 35-48. 
Ege, İlhan - Yaman, Serdar (2018), “TOPSIS ve MOORA Yöntemleri ile Ölçülen Finansal Performansın Pay Getirilerine Etkisi: BIST Çimento-Beton İşletmeleri Üzerine Bir Panel Veri Uygulaması", Al-Farabi Uluslararası Sosyal Bilimler Dergisi, 2(1), ss. 7596.

Elitaş, Cemal - Eleren, Ali - Yıldız, Feyyaz - Doğan, Mesut (2012), "Gri İlişkisel Analiz İle Sigorta Şirketlerinin Performanslarının Belirlenmesi", 16. Finans Sempozyumu, ss. 521-530.

Erdoğan, Mahmut - Yamaltdinova, Adilya (2018), "Borsa İstanbul'a Kayıtlı Turizm Şirketlerinin 2011-2015 Dönemi Finansal Performanslarının TOPSIS ile Analizi”, Optimum Ekonomi ve Yönetim Bilimleri Dergisi, 5(1), ss. 19-36.

Erdoğan, Namık Kemal - Altınırmak, Serpil - Karamaşa, Çağlar (2016), "Comparison of Multi Criteria Decision Making (MCDM) Methods with Respect to Performance of Food Firms Listed in BIST", Copernican Journal of Finance \& Accounting, 5(1), pp. 67-90.

Ergül, Nuray (2014), "BIST-Turizm Sektöründeki Şirketlerin Finansal Performans Analizi”, Çankırı Karatekin Üniversitesi İİBF Dergisi, 4(1), ss. 325-340.

Erol, İsmail - Ferrell Jr, William G.(2009), "Integrated Approach for Reorganizing Ppurchasing: Theory and a Case Analysis on a Turkish Company", Computers \& Industrial Engineering, 56(4), pp. 1192-1204.

Ertuğrul, İrfan - Karakaşoğlu, Nilsen (2009), "Performance Evaluation of Turkish Cement Firms with Fuzzy Analytic Hierarchy Process and TOPSIS Methods", Expert Systems with Applications, 36(1), pp. 702-715.

Esbouei, Saber Khalili - Ghadikolaei, Abdolhamid Safaei - Antucheviciene, Jurgita (2014), "Using FANP and Fuzzy VIKOR for Ranking Manufacturing Companies Based on Their Financial Performance", Economic Computation \& Economic Cybernetics Studies \& Research, 48(3), pp. 141-162.

Feng, Cheng-Min - Wang, Rong-Tsu (2000), "Performance evaluation for airlines including the consideration of financial ratios", Journal of Air Transport Management, 6, pp. 133-142.

Fenyvesa, Veronika - Tarnóczia, Tibor - Zsidóa, Kinga (2015),"Financial Performance Evaluation of Agricultural Enterprises with DEA Method", Procedia Economics and Finance, 32, pp. 423-431.

Ghadikolaei, Abdolhamid Safaei - Esbouei, Saber Khalili - Antucheviciene, Jurgita (2014), "Applying Fuzzy MCDM for Financial Performance Evaluation of Iranian Companies", Technological and Economic Development of Economy, 20(2), pp. 274291. 
Gigović, Ljubomir - Pamučar, Dragan - Bajić, Zoran - Milićević, Milić (2016), "The Combination of Expert Judgment and GIS-MAIRCA Analysis for the Selection of Sites for Ammunition Depots", Sustainability, 8(4), pp. 1-30.

Gök-Kısa, A. Cansu - Perçin, Selçuk (2018), "Bütünleşik Entropi Ağırlık-VIKOR Yöntemi İle Bilişim Teknolojisi Sektöründe Performans Ölçümü”. Ekonomik ve Sosyal Araştırmalar Dergisi, 14(1), ss. 1-13.

Günay, Fatih - Karadeniz, Erdinç - Dalak, Selda (2018), “Türkiye'de En Yüksek Net Satış Gelirine Sahip 20 Şirketin Finansal Performanslarının Gri İlişkisel Analiz Yöntemiyle İncelenmesi”, Ömer Halisdemir Üniversitesi İktisadi ve İdari Bilimler Fakültesi Dergisi, 11(2), ss. 51-73.

Hadelan, Lari - Rogelj, Mateja Jež - Franić, Ramona (2016), "Multicriterial Assessment of Leading Dairy Companies in Croatia", Custos e Agronegocio, 12 (4), pp. 326-343.

Ho, Chien-Ta., Wu, Yun-Shan (2006), "Benchmarking Performance Indicators for Banks", Benchmarking: An International Journal, 13(1/2), pp. 147-159.

Hsu, Li-Chang - Ou,Shang-Ling - Ou, Yih-Chang (2015), "A Comprehensive Performance Evaluation and Ranking Methodology under a Sustainable Development Perspective", Journal of Business Economics and Management, 16(1), pp. 74-92.

https://www.kap.org.tr/tr/Endeksler, Erişim Tarihi: 04.12.2018.

İç, Yusuf Tansel - Tekin, Muhteşem - Pamukoğlu, Fazıl Ziya - Yıldırım, S. Erdinç (2015), "Kurumsal Firmalar İçin Bir Finansal Performans Karşılaştırma Modelinin Geliştirilmesi”, Gazi Üniversitesi Mühendislik-Mimarlık Fakültesi Dergisi, 30(1), ss. 71-85.

Ignatius, J.- Behzadian, M. - Malekan, H. S. - Lalitha, D. (2012), "Financial Performance of Iran's Automotive Sector based on PROMETHEE II", Proceedings of the 2012 IEEE ICMIT, 11-13 June, 2012, pp. 35-38.

İslamoglu, Mehmet - Apan, Mehmet - Öztel, Ahmet (2015), “An Evaluation of the Financial Performance of REITS in Borsa Istanbul: A Case Study Using the Entropy-Based TOPSIS Method”, International Journal of Financial Research, 6(2), pp. 124-138.

Javadin, Seyed Reza Seyed - Esbouei,Saber Khalili -Rajabani, Neda (2016), "An Integrated Assessment of Companies Based on Value Based Measures in Fuzzy Environment". Boletim da Sociedade Paranaense de Matematica, 34(2), pp. 87-98.

Kalogeras, Nikos - Baourakis, George - Zopounidis, Costantin - van Dijk, Gert (2005), "Evaluating the Financial Performance of Agri-Food Firms: AMulticriteria DecisionAid Approach", Journal of Food Engineering, 70, pp. 365-371.

Kaplanoğlu, Emre (2018),“ARAS ve COPRAS Yöntemleriyle Nakit Akışına Dayalı Performans Ölçümü: BIST Kimya, Petrol, Kauçuk Ve Plastik Ürünler Sektöründe Bir Uygulama” Muhasebe ve Vergi Uygulamaları Dergisi, 11(2), ss. 153-184. 
Karaoğlan, Serhat - Şahin, Serap (2018), "BİST XKMYA İşletmelerinin Finansal Performanslarının Çok Kriterli Karar Verme Yöntemleri İle Ölçümü ve Yöntemlerin Karşılaştırılması", Ege Akademik Bakış, 18(1), ss. 63-80.

Kazan, Halim - Ertok, Merve - Ciftçi, Cihan (2015), “Application of a Hybrid Method in the Financial Analysis of Firm Performance", Procedia-Social and Behavioral Sciences, 195, pp. 403-412.

Kızıltoprak, Sinan - Aksoy, Mine (2018), “Borsa İstanbul'da İşlem Gören Aile İşletmelerinin Finansal Performanslarının Analizi”, Ege Akademik Bakış, 18(1), ss. 135-152.

Konak, Tuba - Elbir, Gözde - Yılmaz, Süreyya - Karataş, Bedii Murat - Durman, Yasin Düzakın, Hatice (2018), "Borsa İstanbul'da İşlem Gören Tekstil Firmalarının TOPSIS ve MOORA Yöntemi ile Analizi”, Çukurova Üniversitesi İIBF Dergisi, 22(1), ss. 1144.

Korkmaz, Mehmet - Güner, Demet (2018), "Financial Performance Evaluation of Forest Village Cooperatives: A Multi-Criteria TOPSIS Approach”, CERNE, 24(3), pp. 280287.

Kung, Jung-Yuan - Chuang, Tzung-Nan - Ky, Chau Minh (2011), “A Fuzzy MCDM Method to Select the Best Company Based on Financial Report Analysis", IEEE International Conference on Fuzzy Systems, 27-30 June, 2011, Taipei, Taiwan, 2013-2017.

Lee, Paul Tae-Woo - Lin, Cheng-Wei - Shin, Sung-Ho (2012), "A Comparative Study on Financial Positions of Shipping Companies in Taiwan and Korea using Entropy and Grey Relation Analysis", Expert Systems with Applications 39(5), pp. 5649-5657.

Mandic, Ksenija - Delibasic, Boris - Knezevic, Snezana - Benkovic, Sladjana (2014), "Analysis of the Financial Parameters of Serbian Banks through the Application of the Fuzzy AHP and TOPSIS Methods", Economic Modelling, 43, pp. 30-37.

Meydan, Cebrail - Yıldırım, Bahadır Fatih - Senger, Ötüken (2016), “BIST’te İşlem Gören Gıda İşletmelerinin Finansal Performanslarının Gri İlişkisel Analiz Yöntemi Kullanılarak Değerlendirilmesi”, Muhasebe ve Finansman Dergisi, 69, ss. 147-165.

Moghimi, Rohollah - Anvari, Alireza (2014), “An Integrated FuzzyMCDMApproach and Analysis to Evaluate the Financial Performance of Iranian Cement Companies", International Journal of Advanced Manufacturing Technology, 71, pp. 685-698.

Ömürbek, Nuri - Eren, Hande(2016), "PROMETHEE, MOORA ve COPRAS Yöntemleri İle Oran Analizi Sonuçlarının Değerlendirilmesi: Bir Uygulama”, Mehmet Akif Ersoy Üniversitesi Sosyal Bilimler Enstitüsü Dergisi, 8(16), ss. 174-187.

Ömürbek, Nuri - Karaatlı, Meltem - Balc1, Halil Furkan (2016), "Entropi Temelli MAUT ve SAW Yöntemleri ile Otomotiv Firmalarının Performans Değerlemesi”, Dokuz Eylül Üniversitesi İktisadi ve İdari Bilimler Fakültesi Dergisi, 31(1), ss. 227- 255. 
Ömürbek, Nuri - Mercan, Yasin (2014), "İmalat Alt Sektörlerinin Finansal Performanslarının TOPSIS ve ELECTRE Yöntemleri İle Değerlendirilmesi”, Çankırı Karatekin Üniversitesi İİBF Dergisi, 4(1), ss. 237-266.

Önder, Emrah - Altıntaş, A. Taylan (2017), "Financial Performance Evaluation of Turkish Construction Companies in Istanbul Stock Exchange (BIST)", International Journal of Academic Research in Accounting, Finance and Management Sciences, 7(3), pp. 108113.

Orçun, Çağatay - Eren, Binali Selman. (2017), "TOPSIS Yöntemi ile Finansal Performans Değerlendirmesi: XUTEK Üzerinde Bir Uygulama”, Journal of Accounting \& Finance, (75), ss. 139-154.

Özçelik, Hakan - Küçükçakal, Zühal (2019), "BIST'de İşlem Gören Finansal Kiralama ve Faktoring Şirketlerinin Finansal Performanslarının TOPSIS Yöntemi ile Analizi”, Muhasebe ve Finansman Dergisi, 81, ss. 249-270.

Özdağoğlu, Aşkın - Yakut, Enis - Bahar, Sezai (2017), "Machine selection in a dairy product company with Entropy and SAW method integration", Dokuz Eylül Üniversitesi İktisadi ve İdari Bilimler Fakültesi Dergisi, 32(1), ss. 341-359.

Özden, Ünal H. - Deniz Başar, Özlem - Bağdatlı Kalkan, Seda (2012), “IMKB'de İşlem Gören Çimento Sektöründeki Şirketlerin Finansal Performanslarının VIKOR Yöntemi İle Stralanması", İstanbul Üniversitesi İktisat Fakültesi Ekonometri ve İstatistik Dergisi, 17(1), ss. 23-44.

Pamucar, Dragan S. - Tarle, Snezana Pejcic - Parezanovic, Tanja (2018), "New Hybrid MultiCriteria Decision-Making DEMATEL-MAIRCA Model: Sustainable Selection of a Location for the Development of Multimodal Logistics Centre", Economic ResearchEkonomska istraživanja, 31(1), pp. 1641-1665.

Pamučar, Dragan - Mihajlović, Milan - Obradović, Radojko - Atanasković, Predrag (2017), "Novel Approach to Group Multi-Criteria Decision Making Based on Interval Rough Numbers: Hybrid DEMATEL-ANP-MAIRCA Model", Expert Systems with Applications, 88, pp. 58-80.

Peker, İskender - Baki, Birdoğan (2011), "Gri İlişkisel Analiz Yöntemiyle Türk Sigortacılık Sektöründe Performans Ölçümü”. Uluslararası İktisadi ve İdari İncelemeler Dergisi, 4(7), ss. 1-17.

Robelo, João Fernandes - Leal y, Carmem Teresa - Teixeira, Ânia (2017), "Management and Financial Performance of Agricultural Cooperatives: ACase of Portuguese Olive Oil Cooperatives", REVESCO, 123, ss. 225-249.

Saldanl, Arif - Sırma, İbrahim (2014), “TOPSIS Yönteminin Finansal Performans Göstergesi Olarak Kullanılabilirliği”, Marmara Üniversitesi Öneri Dergisi, 41, ss. 185-202.

Sarıkamış, Cevat (2007), "Rasyo Analizi Uygulamasının Gelişimi”, Muhasebe ve Finansman Dergisi, 33, ss. 44-45. 
Seçme, Neşe Yalçın - Bayrakdaroğlu, Ali - Kahraman, Cengiz (2009), "Fuzzy Performance Evaluation in Turkish Banking Sector Using Analytic Hierarchy Process and TOPSIS" Expert Systems with Applications, 36(9), pp. 11699-11709.

Shaverdi, Meysam - Ramezani, Iman - Tahmasebi, Reza - Rostamy, Ali Asghar Anvary (2016), "Combining Fuzzy AHP and Fuzzy TOPSIS with Financial Ratios to Design a Novel Performance Evaluation Model”, International Journal of Fuzzy Systems, 18(2), pp. 248-262.

Shen, Kao-Yi - Tzeng, Gwo-Hshiung (2015a), "Combining DRSA Decision-Rules with FCABased DANP Evaluation for Financial Performance Improvements",Technological and Economic Development Of Economy, Article in Press, doi:10.3846/20294913.2015.1071295.

Shen, Kao-Yi - Tzeng, Gwo-Hshiun(2015b), “A Decision Rule-Based Soft Computing Model for Supporting Financial Performance Improvement of the Banking Industry", Soft Computing, 19(4), pp. 859-874.

Tavana, Madjid - Khalili-Damghani, Kaveh - Rahmatian, Rahman (2015), “A Hybrid Fuzzy MCDM Method for Measuring the Performance of Publicly Held Pharmaceutical Companies", Annals of Operations Research, 226, pp. 598-621.

Tayyar, Nezih - Akcanlı, Fatma - Genç, Erhan - Erem Ceylan, Işıl (2014), “BIST’e Kayıtlı Bilişim ve Teknoloji Alanında Faaliyet Gösteren İşletmelerin Finansal Performanslarının Analitik Hiyerarşi Prosesi (AHP) ve Gri İlişkisel Analiz (GİA) Yöntemiyle Değerlendirilmesi”, Muhasebe ve Finansman Dergisi, (61), ss. 19-40.

Toma, Elena (2017), "Ranking European COPFarms in Terms of Financial Viability Through a PCA-TOPSIS Approach", Scientific Papers Series Management, Economic Engineering in Agriculture and Rural Development, 17 (2), pp. 381-386.

Tseng, Fang-Mei - Chiu, Yu-Jing - Chen, Ja-Shen (2009), "Measuring Business Performance in the High-Tech Manufacturing Industry: A Case Study of Taiwan's Large-Sized TFT-LCD Panel Companies”, Omega, 37, pp. 686-697.

Tung, Che-Tsung - Lee, Yu-Je (2009), “A Novel Approach to Construct Grey Principal Component Analysis Evaluation Model”, Expert Systems with Applications, 36, pp. 5916-5920.

Tung, Che-Tsung - Lee, Yu-Je (2010),"The İnnovative Performance Evaluation Model of Grey Factor Analysis: A Case Study of Listed Biotechnology Corporations in Taiwan”, Expert Systems with Applications, 37, pp. 7844-7851.

Tütüncü, Lokman - Uysal, Zafer (2018), "Testing a Simple Financial Alternative to TOPSIS for Financial Performance Measurement", Muhasebe ve Finansman Dergisi, (78), ss. 249-264. 
Üçüncü, Tutku - Akyüz, Kadri Cemil - Akyüz, İlker - Bayram, Bahadır Çağrı - Ersen, Nadir (2018), "Evaluation offinancial performance of paper companies traded at BIST with TOPSIS method", Kastamonu Üniversitesi Orman Fakültesi Dergisi, 18(1), ss. 92-98.

Uludağ, Ahmet Serhat - Ece, Oğuzhan (2018). “Türkiye'de Faaliyet Gösteren Mevduat Bankalarının Finansal Performanslarının TOPSIS Yöntemi Kullanılarak Değerlendirilmesi”, Finans Politik \& Ekonomik Yorumlar, 55(637), ss. 49-80.

Ünlü, Ulaş - Yalçın, Neşe - Yağlı, İbrahim (2017), “Kurumsal Yönetim ve Firma Performansı: TOPSIS Yöntemi ile BIST 30 Firmaları Üzerine Bir Uygulama”, Dokuz Eylül Üniversitesi Sosyal Bilimler Enstitüsü Dergisi, 19 (1), ss. 63-81.

Varmazyar, M. - Dehghanbaghi, M. - Afkhami, M. (2016), “A Novel Hybrid MCDM Model for Performance Evaluation of Research and Technology Organizations Based on BSC Approach", Evaluation and Program Planning, 58, pp. 125-140.

Visalakshmi, S. - Lakshmi, P. - Shama, M.S. - Vijayakumar, Kamala (2015), “An Integrated Fuzzy DEMATEL-TOPSIS Approach for Financial Performance Evaluation of GREENEX Industries", International Journal of Operational Research, 23(3), pp. 340362.

Wang, Tien-Chin - Lee, Hsien-Da (2009), "Developing a Fuzzy TOPSIS Approach Based on Subjective Weights and Objective Weights", Expert Systems with Applications, 6(5), pp. 8980-8985.

Wang, Yu-Jie (2008), "Applying FMCDM to Evaluate Financial Performance of Domestic Airlines in Taiwan", Expert Systems with Applications, 34(3), pp. 1837- 1845.

Wang, Yu-Jie (2009), "Combining Grey Relation Analysis with FMCGDM to Evaluate Financial Performance of Taiwan Container Lines", Expert Systems with Applications, 36(2), pp. 2424-2432.

Wang, Yu-Jie (2014), "The Evaluation of Financial Performance for Taiwan Container Shipping Companies by Fuzzy TOPSIS”, Applied Soft Computing, 22, pp. 28-35.

Wang, Yu-Jie - Lee, Hsuan Shih. (2010), "Evaluating Financial Performance of Taiwan Container Shipping Companies by Strength and Weakness Indices", International Journal of Computer Mathematics, 87(1), pp. 38-52.

Wanke, Peter - Kalam Azad, Md Abul - Barros, C. P. - Had1-Vencheh, Abdollah (2016), "Predicting Performance in ASEAN Banks: An Integrated Fuzzy MCDM- Neural Network Approach”, Expert Systems, 33(3), pp. 213-229.

Wiratno, Stefanus Eko - Litiffianti, Effi - Wirawan, Kevin Karmadi (2015),"Selection of Business Funding Proposals Using Analytic Network Process: ACase Study at a Venture Capital Company", Procedia Manufacturing, 4, pp. 237 - 243. 
Yalçın Seçme, Neşe - Bayrakdaroğlu, Ali - Kahraman, Cengiz (2009), "Fuzzy Performance Evaluation In Turkish Banking Sector Using Analytic Hierarchy Process and TOPSIS", Expert Systems with Applications, 36, pp. 11699-11709.

Yalçın, Neşe - Bayrakdaroğlu, Ali - Kahraman, Cengiz (2012),“Application of Fuzzy MultiCriteria Decision Making Methods for Financial Performance Evaluation of Turkish Manufacturing Industries", Expert Systems with Applications, 39, pp. 350-364.

Yalçın, Neşe - Ünlü, Ulaş (2018),“A Multi-Criteria Performance Analysis of Initial Public Offering (IPO) Firms Using CRITIC and VIKOR Methods", Technological and Economic Development of Economy, 24(2), pp. 534-560.

Yıldırım, Murat - Altan, İnci Merve - Gemici, Rafet (2018), "Kurumsal Yönetim İle Finansal Performans Arasındaki İlişkinin Entropi Ağırlıklandırmalı TOPSIS Yöntemi İle Değerlendirilmesi: BIST'te İşlem Gören Gıda ve İçecek Şirketlerinde Bir Araştırma”, Muhasebe ve Vergi Uygulamaları Dergisi (Muvu)/Journal Of Accounting \& Taxation Studies (Jats), 11(2), ss. 130-152.

Yükçü, Süleyman - Kaplanoğlu, Emre (2015), “Çok Kriterli Karar Verme Yöntemleriyle Gözaltı Pazarı Şirketlerinin Finansal Performanslarının Belirlenmesi”, World of Accounting Science, 17(3), ss. 687-616.

Zhang, Hong - Gu, Chao-lin - Gu, Lu-wen - Zhang, Yan (2011), "The Evaluation of Tourism Destination Competitiveness by TOPSIS \&Information Entropy-A case in the Yangtze River delta of China", Tourism Management, 32(2), pp. 443-451.

Zhao, Huiru - Li, Nana (2015), "Evaluating the Performance of Thermal Power Enterprises Usingsustainability Balanced Scorecard, Fuzzy Delphic and Hybrid Multi-Criteria Decision Making Approaches for Sustainability", Journal of Cleaner Production, 108, pp. 569-582. 